\title{
Physical characteristics and occurrence rates of meteoric plasma layers detected in the Martian ionosphere by the Mars Global Surveyor Radio Science Experiment
}

\author{
Paul Withers, ${ }^{1}$ M. Mendillo, ${ }^{1}$ D. P. Hinson, ${ }^{2}$ and K. Cahoy ${ }^{2}$ \\ Received 23 July 2008; revised 23 September 2008; accepted 14 October 2008; published 30 December 2008.
}

[1] Low-altitude plasma layers are present in 71 of 5600 electron density profiles from the Martian ionosphere obtained by the Mars Global Surveyor Radio Science experiment. These layers are produced by the ablation of meteoroids and subsequent ionization of meteoric atoms. The mean altitude of the meteoric layer is $91.7 \pm 4.8 \mathrm{~km}$. The mean peak electron density in the meteoric layer is $(1.33 \pm 0.25) \times 10^{10} \mathrm{~m}^{-3}$. The mean width of the meteoric layer is $10.3 \pm 5.2 \mathrm{~km}$. The occurrence rate of meteoric layers varies with season, solar zenith angle, and latitude. Seasonal variations in occurrence rate are particularly strong, often exceeding an order of magnitude. Meteoric layer altitude, peak electron density, and width are all positively correlated, with correlation coefficients of $0.3-0.4$. Other correlation coefficients between the physical characteristics of meteoric layers and atmospheric or observational properties, such as scale height, solar zenith angle, and solar flux, have absolute values that are significantly smaller, indicating lack of correlation. The photochemical lifetime of plasma in meteoric layers is $\sim 12$ days and depends on altitude.

Citation: Withers, P., M. Mendillo, D. P. Hinson, and K. Cahoy (2008), Physical characteristics and occurrence rates of meteoric plasma layers detected in the Martian ionosphere by the Mars Global Surveyor Radio Science Experiment, J. Geophys. Res., 113, A12314, doi:10.1029/2008JA013636.

\section{Introduction}

[2] All planets and satellites in the solar system sweep through interplanetary dust as they move along their orbital paths. When dust particles, known as meteoroids, enter an atmosphere at orbital speeds, they decelerate and experience ablation. Optical and radio emissions are produced, and other physical and chemical processes also occur.

[3] In particular, the interaction of high-speed meteoroids and atmospheric gases leads to the deposition in the planetary atmosphere of species that would otherwise be absent, such as neutral $\mathrm{Mg}$ or Fe. Related ions, such as $\mathrm{Mg}^{+}$ or $\mathrm{Fe}^{+}$, are also produced. These ions may be produced directly during meteoroid ablation by the impact ionization of ablated neutral metal atoms in collisions with atmospheric molecules, indirectly by photoionization of neutral metal atoms, or indirectly by charge exchange between neutral metal atoms and atmospheric ions. Meteoroid influx therefore modifies vertical profiles of plasma density in a planetary ionosphere. Layers of meteoric plasma are formed whose peaks lie below the peaks of plasma layers produced by photoionization of major constituents of the neutral

\footnotetext{
${ }^{1}$ Center for Space Physics, Boston University, Boston, Massachusetts, USA.

${ }^{2}$ Department of Electrical Engineering, Stanford University, Stanford, California, USA.
}

Copyright 2008 by the American Geophysical Union. 0148-0227/08/2008JA013636 atmosphere. Such layers, called meteoric layers, have been observed in the ionospheres of Earth [Grebowsky and Aikin, 2002], Venus [Pätzold et al., 2008] and Mars [Pätzold et al., 2005].

[4] We conduct the first comprehensive search for lowaltitude plasma layers in electron density profiles acquired by the Mars Global Surveyor (MGS) Radio Science (RS) experiment [Tyler et al., 1992, 2001; Hinson et al., 1999], and we use the results to extend the characterization of recently discovered meteoric layers on Mars. The MGS RS data set is well suited to investigations of low-altitude layers in the Martian ionosphere because it contains many electron density profiles (5600), spans multiple years and Martian seasons (1998-2005), and is available in digital format from a public archive. The specific objectives of this paper are to determine the frequency with which meteoric layers occur in the Martian ionosphere, quantify their physical characteristics, and investigate what processes influence their occurrence rate and physical characteristics.

[5] We first describe the effects of meteoroids on planetary ionospheres and introduce the MGS RS data set. We discuss the challenges of detecting plasma layers at low altitudes in the MGS electron density profiles, and determine whether the detected layers are meteoric layers. We find the altitude, width and electron density of each meteoric layer, and compare these characteristics to those predicted by theoretical models. We quantify the dependence of meteoric layer occurrence rate on season, latitude and solar zenith angle (SZA), and discuss possible explanations for the 
observed dependences. We investigate relationships between the physical characteristics of meteoric layers, including layer width, electron density and altitude, and neutral atmospheric and observational properties, including scale height, SZA and latitude. Finally, we explore possible causes of variability in the observed characteristics of meteoric layers, and estimate the lifetime of meteoric plasma.

[6] The study of the response of the Martian neutral atmosphere and ionosphere to meteoroid influx is relevant to several topics in planetary science. These include the activity of comets, the dynamics of dust in space, delivery of cometary organic materials to planets, collision hazards for spacecraft, and ionospheric production, loss and transport processes. Meteoric layers may also affect remote sensing, navigation and communication techniques that use radio wavelengths [Witasse et al., 2001; Nielsen et al., 2007].

\section{Effects of Meteoroids on Planetary Ionospheres \\ 2.1. Earth}

[7] In situ measurements by ion mass spectrometers on approximately 50 suborbital rocket flights have shown that metallic ions $\mathrm{Mg}^{+}, \mathrm{Fe}^{+}, \mathrm{Si}^{+}, \mathrm{Ca}^{+}$and $\mathrm{Na}^{+}$are present in layers between 80 and $130 \mathrm{~km}$ altitude in the terrestrial atmosphere [Grebowsky and Aikin, 2002]. Metallic ions are mainly produced by charge exchange reactions between neutral metal atoms and abundant $\mathrm{O}_{2}^{+}$and $\mathrm{NO}^{+}$ions, and by photoionization of neutral metal atoms.

\subsection{Mars}

[8] Here we describe the Martian ionosphere and discuss the predicted effects upon it of meteoroid influx.

[9] The most abundant neutral in the bulk Martian atmosphere is $\mathrm{CO}_{2}$. The abundance of $\mathrm{O}$ is a few percent at the main ionospheric peak, and $\mathrm{O}$ becomes the most abundant neutral at higher altitudes. The dayside ionosphere has a main layer (M2) at optical depth of unity for extreme ultraviolet (EUV) photons $\left(\sim 130 \mathrm{~km}\right.$ for SZA $\left.\sim 70^{\circ}\right)$. There is also a smaller, more variable layer (M1) at lower altitudes, where the optical depth for more penetrating $\sim 5 \mathrm{~nm}$ X-ray photons is unity $\left(\sim 110 \mathrm{~km}\right.$ for SZA $\left.\sim 70^{\circ}\right)$. The labels "M1" and "M2" were introduced by Rishbeth and Mendillo [2004]. $N_{p k}$ and $z_{p k}$ are often used to describe electron density profiles. $N_{p k}$ is the maximum value of $N$, the electron density, and $z_{p k}$ is the altitude, $z$, at which $N=$ $N_{p k} . N_{p k}$ and $z_{p k}$ in all existing dayside observations correspond to the M2 layer, not the M1 layer. The chemistry in these photochemically controlled layers can be summarized as: $\mathrm{CO}_{2}+h v \rightarrow \mathrm{CO}_{2}^{+}+e, \mathrm{CO}_{2}^{+}+\mathrm{O}_{\stackrel{\text { fast }}{\rightarrow}} \mathrm{O}_{2}^{+}+\mathrm{CO}$ and $\mathrm{O}_{2}^{+}+$ $e \stackrel{\text { slow }}{\rightarrow} \mathrm{O}+\mathrm{O}$, which makes $\mathrm{O}_{2}^{+}$the dominant ion [Hanson et $\overrightarrow{a l} ., 1977 ;$ Chen et al., 1978; Fox et al., 1996; Mendillo et al., 2003; Fox, 2004b]. Above $\sim 200 \mathrm{~km}, \mathrm{O}$ becomes the most abundant neutral, $\mathrm{O}^{+}$becomes an important ion, and transport processes strongly influence plasma density [Hanson et al., 1977; Chen et al., 1978].

[10] Two models have predicted that meteoroid influx at Mars creates a plasma layer at $\sim 80-90 \mathrm{~km}[$ Pesnell and Grebowsky, 2000; Molina-Cuberos et al., 2003]. These models suggest that this layer is always present across the dayside. $\mathrm{Mg}^{+}$and $\mathrm{Fe}^{+}$"are produced by direct meteoric ionization, photoionization, and charge exchange with atmospheric ions, mainly $\mathrm{O}_{2}^{+}$" [Molina-Cuberos et al., 2003].
The two models differ on whether photoionization of $\mathrm{Mg}$ and Fe [Pesnell and Grebowsky, 2000] or charge exchange between them and ambient $\mathrm{O}_{2}^{+}$ions [Molina-Cuberos et al., 2003 ] is the dominant production mechanism. Both models predict that $\mathrm{Mg}^{+}$and $\mathrm{Fe}^{+}$are typically converted by chemical reactions into molecular metallic ions, such as $\mathrm{Mg}^{+}$. $\mathrm{CO}_{2}$ and $\mathrm{Fe}^{+} \cdot \mathrm{CO}_{2}$, which are rapidly neutralized by dissociative recombination. Although P. Withers and A. A. Christou (Early observations of meteoric plasma layers in the dayside ionospheres of Venus and Mars, submitted to Geophysical Research Letters, 2008) have suggested that meteoric layers are detectable in some electron density profiles obtained by Mariner 9 in 1971, the theoretical simulations of Pesnell and Grebowsky [2000] and MolinaCuberos et al. [2003] preceded the first detections of Martian meteoric layers [Fox, 2004a; Pätzold et al., 2005; Withers et al., 2006]. Also, infrared remote sensing observations have detected spectral features associated with $\mathrm{Mg}^{+}$ - $\mathrm{CO}_{2}$ [Aikin and Maguire, 2005; Maguire and Aikin, 2006].

\subsection{Venus}

[11] The neutral upper atmospheres and ionospheres of Venus and Mars share many similarities because of the predominance of $\mathrm{CO}_{2}$ and the presence of a few percent of $\mathrm{O}$ at ionospheric altitudes. Pesnell and Grebowsky [2000] suggested that some nightside Pioneer Venus Orbiter (PVO) electron density profiles contain meteoric layers, and Butler and Chamberlain [1976] had earlier suggested that meteoroid influx could produce the surprisingly dense nightside ionosphere. However, recent work has not favored these nightside hypotheses [Fox and Kliore, 1997].

[12] More recently, Witasse and Nagy [2006] suggested that two PVO electron density profiles near the terminator (SZA of $85.6^{\circ}$ and $91.6^{\circ}$ ) contain meteoric layers. Withers and Christou (submitted manuscript, 2008) found that dayside electron density profiles from radio occultation instruments on Mariner 10, Venera 9, Venera 10, PVO and Magellan contain meteoric layers. The Mariner 10 egress profile given by Fjeldbo et al. [1975, Figure 3] is a good example. Definitive detections of meteoric layers have been made by the VeRa radio science instrument on Venus Express [Pätzold et al., 2007, 2008].

\subsection{Other Planets}

[13] Narrow layers below the peaks of the main layers of Jovian planet ionospheres have been attributed to meteoroid influx, although explanations involving electrodynamic effects, dynamical forcing by gravity waves, and charged particle precipitation have also been proposed [e.g., Waite and Cravens, 1987; Lyons, 1995; Hinson et al., 1997, 1998; Moses and Bass, 2000; Kim et al., 2001]. Models have also predicted the presence of a meteoric layer in Titan's ionosphere [Molina-Cuberos et al., 2001].

\section{Available Data}

[14] The only measurements of the Martian ionosphere at predicted meteoric layer altitudes are vertical electron density profiles from radio occultation experiments. Approximately 6500 of these profiles have been measured. 433 of these come from missions that preceded MGS, predominantly from Mariner 9, Viking Orbiter 1 and Viking Orbiter 


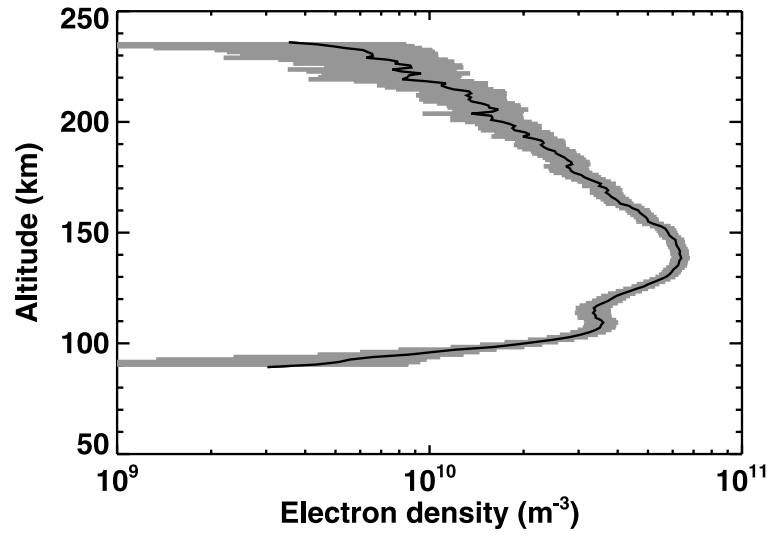

Figure 1. Profile 0337M41A.EDS, a typical MGS RS electron density profile. It was measured at latitude $66.6^{\circ} \mathrm{N}$, longitude $164.3^{\circ} \mathrm{E}, 2.8 \mathrm{~h} \mathrm{LST}, L_{s}=83.9^{\circ}$, and $\mathrm{SZA}=83.0^{\circ}$ on 2 December 2000. The nominal profile is the solid line, and $1 \sigma$ uncertainties in the electron densities are marked by the grey region. Note the M2 layer at $140 \mathrm{~km}$ and the M1 layer at $110 \mathrm{~km}$.

2 [Mendillo et al., 2003]. 5600 come from MGS [Hinson, 2007; Tyler et al., 2007]. Several hundred have been determined by the Mars radio science instrument on Mars Express (MEX), which is still in operation [Pätzold et al., 2004, 2005; P. Withers et al., Comparison of seasonal variations in the meteoric layer of the Martian ionosphere and predicted meteor showers, submitted to Icarus, 2008]. Many more electron density profiles have been obtained by the MARSIS topside radar sounder instrument on MEX, but these do not extend below the M2 layer [Nielsen, 2004; Gurnett et al., 2005; Nielsen et al., 2006; Gurnett et al., 2008; Morgan et al., 2008; Duru et al., 2008].

[15] This paper uses MGS RS electron density profiles only. A typical MGS RS electron density profile is shown in Figure 1, where LST is local solar time and SZA is solar zenith angle. Martian seasons are described by $L_{s}$, the areocentric longitude of the Sun, which is defined as the angle between the Mars-Sun line and the Mars-Sun line at the northern hemisphere vernal equinox. $L_{s}=0^{\circ}$ is the start of northern spring, $L_{s}=90^{\circ}$ is the start of northern summer, $L_{s}=180^{\circ}$ is the start of northern autumn, and $L_{s}=270^{\circ}$ is the start of northern winter. We adopt the convention that Mars year (MY) 1 began on 11 April $1955\left(L_{s}=0^{\circ}\right)$ [Clancy et al., 2000]. The coverage of the MGS data set is shown in Table 1. All longitudes were sampled regularly. The interval between successive profiles was typically $2 \mathrm{~h}$, MGS's orbital period, but was often greater. Latitude, LST, SZA and $L_{s}$ did not change significantly from orbit to orbit. Longitude, meaning longitude relative to the surface of Mars, changed by $\sim 30^{\circ}$ from orbit to orbit.
[16] The typical vertical range of an MGS electron density profile is $90 \mathrm{~km}$ to $210 \mathrm{~km}$. Observed values of $N_{p k}$ vary as the square root of the cosine of SZA in accordance with predictions from Chapman theory [e.g., Hantsch and Bauer, 1990; Withers and Mendillo, 2005]. $N_{p k}$ is typically on the order of $10^{11} \mathrm{~m}^{-3}$ at $70^{\circ}$ and $5 \times 10^{10} \mathrm{~m}^{-3}$ at $85^{\circ}$. Uncertainty in electron density does not vary significantly with altitude for a given profile, but it does vary from profile to profile. The stated uncertainty in electron density has a mean value of $4.6 \times 10^{9} \mathrm{~m}^{-3}$ and a standard deviation of $2.0 \times 10^{9} \mathrm{~m}^{-3}$ [Hinson, 2007; Tyler et al., 2007].

\section{Detection of Low-Altitude Plasma Layers on Mars}

[17] Differences between in situ mass spectrometers and radio occultations must be considered when comparing terrestrial and Martian meteoric layer observations. Meteoric layers are clearly evident in data acquired by in situ mass spectrometers during suborbital rocket flights through the terrestrial ionosphere [Grebowsky and Aikin, 2002]. They are much less distinct in radio occultation measurements of Martian electron density profiles [Pätzold et al., 2005; Withers and Christou, submitted manuscript, 2008]. Visual inspection shows that the M2 layer is always present, and the M1 layer is usually discernible, in Martian dayside electron profiles, although the M1 layer may be a subdued ledge or shoulder, rather than a local maximum [Bougher et $a l ., 2001]$. Visual inspection sometimes identifies an additional layer at lower altitudes, which we label as the $\mathrm{M}_{M}$ layer. Although the origin of these low-altitude plasma layers is not determined until section 6, we adopt the subscript "M," which stands for "meteoric," for labeling purposes. The $\mathrm{M}_{M}$ layer is distinct from the M1 and M2 layers. For example, the profile in Figure 2 has three clear layers at $140 \mathrm{~km}(\mathrm{M} 2), 110 \mathrm{~km}(\mathrm{M} 1)$ and $90 \mathrm{~km}\left(\mathrm{M}_{M}\right)$.

[18] An automatic algorithm was developed to identify occurrences of the $\mathrm{M}_{M}$ layer in the MGS RS electron density profiles (Appendix A). Its results are verifiable and reproducible, unlike the results that would be obtained by manual classification based on visual observation. Nonetheless, this algorithm is not the only possible way to identify low-altitude plasma layers. According to this algorithm, 71 of the 5600 MGS profiles contain low-altitude layers. Some examples are shown in Figures 2-4.

\section{Physical Characteristics of Low-Altitude Layers}

[19] The altitude $\left(z_{M}\right)$, electron density $\left(N_{M}\right)$, and width $\left(L_{M}\right)$, defined as the full width at half maximum, of low-

Table 1. Coverage of MGS Electron Density Profiles

\begin{tabular}{|c|c|c|c|c|c|c|}
\hline Dates & Latitude $\left({ }^{\circ} \mathrm{N}\right)$ & LST & $L_{S}(\mathrm{deg})$ & MY & SZA (deg) & Number \\
\hline 24-31 Dec 1998 & $64.7-67.3$ & $3.3-4.3$ & $74.1-77.3$ & 24 & $78.4-80.8$ & 32 \\
\hline 9-27 Mar 1999 & $69.7-73.3$ & $3.6-4.2$ & $107.6-115.9$ & 24 & $76.5-77.8$ & 43 \\
\hline 6-29 May 1999 & -69.1 to -64.6 & $12.0-12.2$ & $134.7-146.3$ & 24 & $78.5-86.9$ & 220 \\
\hline 1 Nov 2000 to 6 Jun 2001 & $63.4-85.5$ & $2.8-8.8$ & $70.2-173.8$ & 25 & $71.8-86.9$ & 1572 \\
\hline 31 Oct 2002 to 4 Jun 2003 & $60.6-84.4$ & $3.6-14.1$ & $89.0-197.3$ & 26 & $71.0-83.7$ & 1806 \\
\hline 22 Jun to 2 Jul 2003 & $68.4-68.5$ & $13.9-14.1$ & $207.8-214.1$ & 26 & $83.0-85.0$ & 76 \\
\hline 23 Nov 2004 to 9 Jun 2005 & $61.8-80.1$ & $4.4-14.7$ & $119.0-227.3$ & 27 & $73.2-89.2$ & 1851 \\
\hline
\end{tabular}




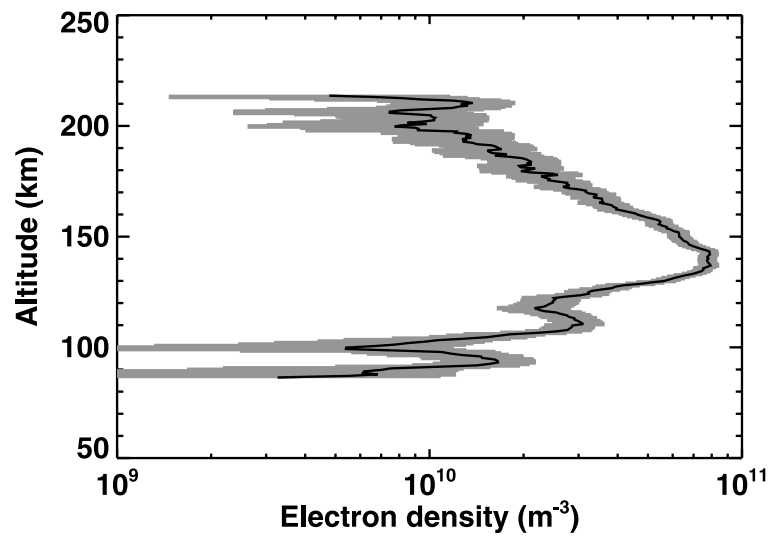

Figure 2. MGS RS profile 5045K56A.EDS has three clear layers, the M2 layer at $140 \mathrm{~km}$, the M1 layer at $110 \mathrm{~km}$, and the $\mathrm{M}_{M}$ layer at $90 \mathrm{~km}$. It was measured at latitude $79.9^{\circ} \mathrm{N}$, longitude $316.0^{\circ} \mathrm{E}, 9.9 \mathrm{~h} \mathrm{LST}, L_{s}=160.1^{\circ}$, and $\mathrm{SZA}=73.2^{\circ}$ on 14 February 2005. Lines and shading as Figure 1.

altitude $\mathrm{M}_{M}$ layers can be characterized. Values of $z_{M}, N_{M}$ and $L_{M}$ were determined as described in Appendix B, and are shown in Figures 5-7. Uncertainties were also determined. The weighted mean value of $z_{M}$ is $91.7 \mathrm{~km}$ and its standard deviation is $4.8 \mathrm{~km}$. Profiles that contain lowaltitude $\mathrm{M}_{M}$ layers often extend below the typical vertical range of 90 to $210 \mathrm{~km}$. Corresponding values are $(1.33 \pm$ $0.25) \times 10^{10} \mathrm{~m}^{-3}$ for $N_{M}$ and $10.3 \pm 5.2 \mathrm{~km}$ for $L_{M}$. The mean value of $\sigma_{z m}$, the uncertainty in a single $z_{M}$, is $0.72 \mathrm{~km}$. Corresponding values are $4.7 \times 10^{9} \mathrm{~m}^{-3}$ for $\sigma_{N m}$ and $1.44 \mathrm{~km}$ for $\sigma_{L m}$.

\section{Are Low-Altitude Plasma Layers Meteoric Layers?}

[20] Low-altitude electron densities can be enhanced by several mechanisms, including meteoroid influx, solar flares and solar energetic particles [Mendillo et al., 2006; Morgan et al., 2006; Espley et al., 2007].

[21] Two publications have made detailed predictions about meteoric layers in the Martian ionosphere. Pesnell

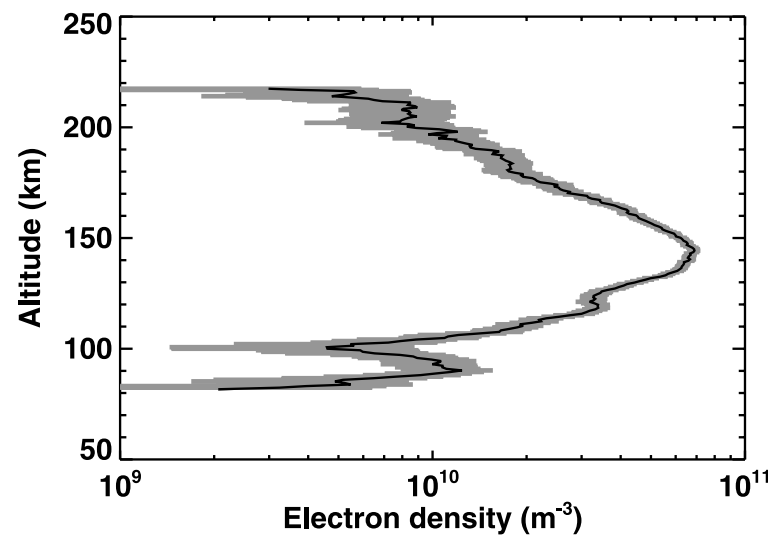

Figure 3. MGS RS profile 5127R00A.EDS also contains the $\mathrm{M}_{M}$ layer. It was measured at latitude $66.0^{\circ} \mathrm{N}$, longitude $2.4^{\circ} \mathrm{E}, 14.4 \mathrm{~h} \mathrm{LST}, L_{s}=206.8^{\circ}$, and $\mathrm{SZA}=81.6^{\circ}$ on 7 May 2005. Lines and shading as Figure 1.

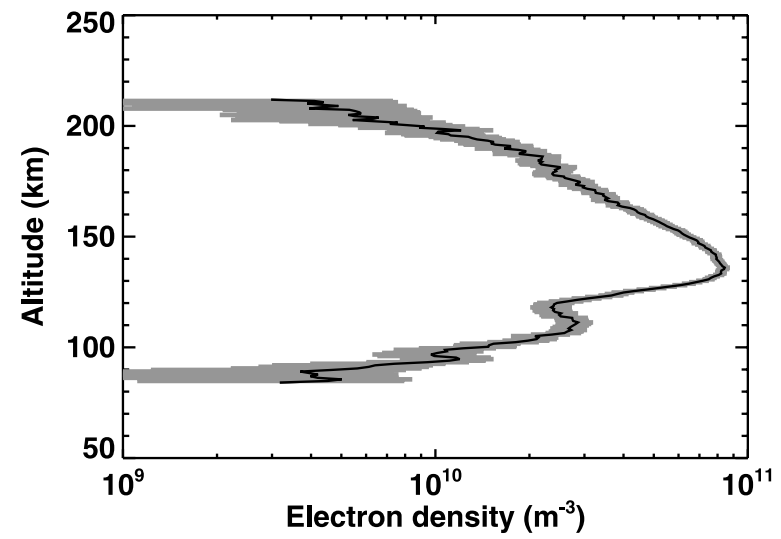

Figure 4. MGS RS profile 3154P03A.EDS has four layers, the M2 layer at $140 \mathrm{~km}$, the M1 layer at $110 \mathrm{~km}$, and two meteoric layers at 95 and $85 \mathrm{~km}$. It was measured at latitude $69.2^{\circ} \mathrm{N}$, longitude $84.7^{\circ} \mathrm{E}, 14.1 \mathrm{~h} \mathrm{LST}, L_{s}=196.6^{\circ}$, and SZA $=79.5^{\circ}$ on 3 June 2003. Lines and shading as Figure 1.

and Grebowsky [2000] use Mg as a proxy for all metallic species, and their Figure 5 shows a predicted vertical profile of $\mathrm{Mg}^{+}$that contains a layer at $78 \mathrm{~km}$ with electron densities of $1.6 \times 10^{10} \mathrm{~m}^{-3}$ and a full width at half maximum of $20 \mathrm{~km}$. Figure 5 of the independent work of MolinaCuberos et al. [2003] shows a predicted vertical profile of $\mathrm{Mg}^{+}$containing a layer at $89 \mathrm{~km}$ with electron densities of $1.0 \times 10^{10} \mathrm{~m}^{-3}$ and a full width at half maximum of $24 \mathrm{~km}$.

[22] Predicted meteoric layer altitudes are within one scale height of the mean observed altitude. Predicted meteoric layer electron densities bracket the mean observed electron density. Predicted meteoric layer widths are within a factor of two of the mean observed width. Comparison of the shapes of observed and predicted meteoric layers (symmetric about $z_{M}$, such as the shape of a Gaussian distribution, or asymmetric about $z_{M}$, such as the shape of a Chapman layer) may be productive in the future.

[23] Solar flares cause enhanced electron densities at $120 \mathrm{~km}$ and below, and increase the electron density in

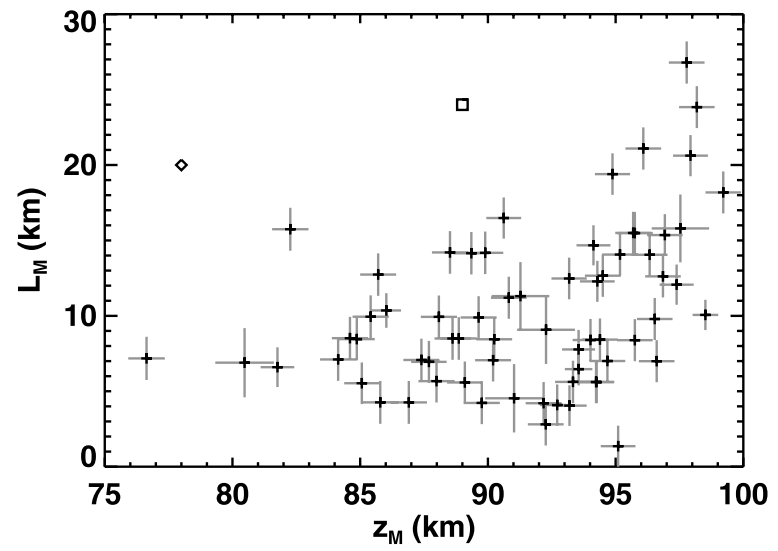

Figure 5. Distribution of $z_{M}$ and $L_{M}$ (black crosses). Uncertainties $\sigma_{z m}$ and $\sigma_{L m}$ are shown as grey lines. Values from Pesnell and Grebowsky [2000] are indicated by a diamond, and values from Molina-Cuberos et al. [2003] are indicated by a square. 


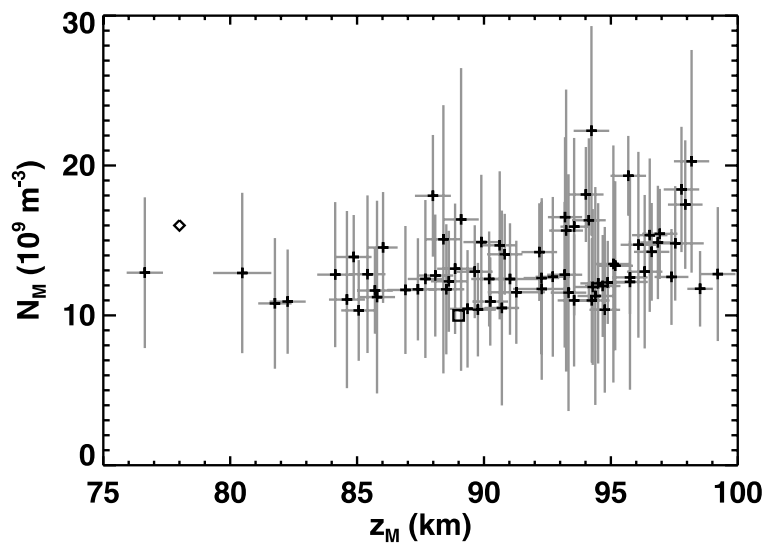

Figure 6. As Figure 5 but $z_{M}$ and $N_{M}$.

the M1 layer. We now demonstrate that solar flares did not cause the low-altitude $\mathrm{M}_{M}$ layers found by application of the algorithm in Appendix A. We have previously identified $\sim 10$ MGS profiles that appear to be affected by solar flares [Mendillo et al., 2006]; application of the algorithm in Appendix A did not identify a low-altitude plasma layer in any of those profiles. A typical electron density profile satisfies $d N / d z>0$ at altitudes below $100 \mathrm{~km}$, where $N$ is electron density and $z$ is altitude. Models do not suggest that solar flares cause $d N / d z<0$ at altitudes below $100 \mathrm{~km}$ [Bougher et al., 2001; Fox, 2004b]. All 71 low-altitude layers identified by application of the algorithm in Appendix A have $d N / d z<0$ at some altitude below $100 \mathrm{~km}$. This corresponds to the topside of the layer. Additional confirmation that the low-altitude plasma layers identified by this algorithm are not produced by solar flares comes from solar observations. The largest solar flare observed at Earth on a day when low-altitude $\mathrm{M}_{M}$ layers were observed on Mars by MGS was an M7 class flare, which is a moderate flare. Solar flares are classified as "moderate" (M) or "extreme" (X) if their maximum flux at $1 \mathrm{AU}$, integrated from 0.1 to $0.8 \mathrm{~nm}$, is $10^{-5}-10^{-4} \mathrm{~W} \mathrm{~m}^{-2}$ or $>10^{-4} \mathrm{~W} \mathrm{~m}^{-2}$, respectively. Note that an M1 class flare and an M1 ionospheric layer are different. Of the 71 low-altitude $\mathrm{M}_{M}$ layers found on Mars, only 16 were observed on a day when a solar flare stronger than an M1 class flare was observed at Earth. The Sun's flare activity was low on most of the days on which lowaltitude $\mathrm{M}_{M}$ layers were observed. Only 2 of these $\mathrm{M}$ class

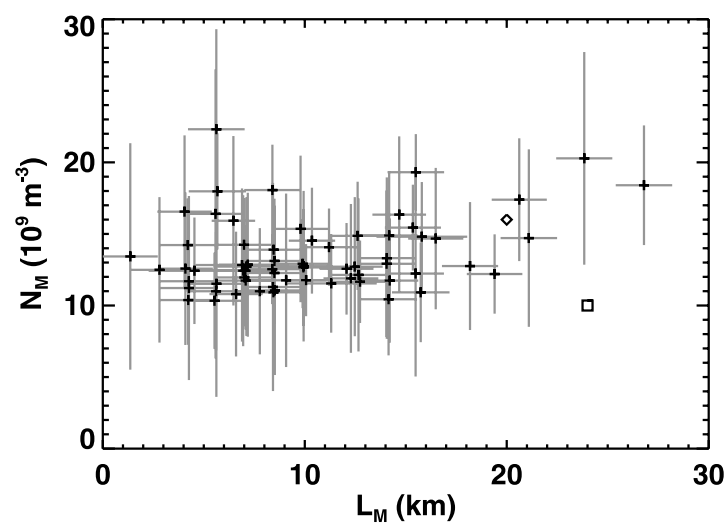

Figure 7. As Figure 5 but $L_{M}$ and $N_{M}$. flares occurred during a $1 \mathrm{~h}$ interval before the observation of a low-altitude $\mathrm{M}_{M}$ layer. $\mathrm{M}$ class flares that occur after, or more than $1 \mathrm{~h}$ before, an ionospheric observation will have no detectable effect on the observed profile [Mendillo et al., 2006]. On the basis of electron density gradients and solar observations, we conclude that the low-altitude plasma layers identified by this algorithm are not produced by solar flares.

[24] Typical solar wind protons traveling at $400 \mathrm{~km} \mathrm{~s}^{-1}$ do not penetrate below $100 \mathrm{~km}$ [Kallio and Janhunen, 2001; Haider et al., 2002]. Energies of precipitating particles increase significantly during solar energetic particle events associated with coronal mass ejections. However, energy deposition rates are maximized near $100 \mathrm{~km}$, significantly above the peak of meteoric layers [Leblanc et al., 2002]. No published predictions suggest that solar energetic particles produce a narrow layer of plasma at $80-90 \mathrm{~km}$ altitude. Also, solar energetic particle events and coronal mass ejections are usually associated with solar activity, and all 71 low-altitude $\mathrm{M}_{M}$ layers were observed when no extreme solar flares were observed. We conclude that the lowaltitude $\mathrm{M}_{M}$ layers identified by this algorithm are not produced by solar energetic particle events.

[25] At least three profiles, 3154P03A.EDS (Figure 4), 5021P54A.EDS and 5104T33A.EDS, contain multiple plasma layers below $100 \mathrm{~km}$. Profiles 3154 P03A.EDS $\left(69.2^{\circ} \mathrm{N}\right.$, $\mathrm{LST}=14.1 \mathrm{~h}$ (one "hour" of local solar time on Mars corresponds to $1 / 24$ of a Martian day), $L_{s}=196.6^{\circ}, \mathrm{SZA}=$ $79.5^{\circ}, 3$ June 2003) and 5104T33A.EDS $\left(69.1^{\circ} \mathrm{N}, \mathrm{LST}=\right.$ $13.9 \mathrm{~h}, L_{s}=193.2^{\circ}, \mathrm{SZA}=77.4^{\circ}, 14$ April 2005) were measured under very similar conditions, but 1 Mars year apart. Multiple terrestrial meteoric layers are common [Grebowsky and Aikin, 2002]. A single population of charged particles must have a highly unusual energy distribution to produce multiple low-altitude plasma layers.

[26] No compositional information is available to determine whether ions in low-altitude $\mathrm{M}_{M}$ layers are metallic or not, although infrared remote sensing observations of the Martian atmosphere have detected spectral features associated with $\mathrm{Mg}^{+} \cdot \mathrm{CO}_{2}$ [Aikin and Maguire, 2005; Maguire and Aikin, 2006].

[27] Because of the consistency between observations and meteoroid-based predictions, and weaknesses identified in

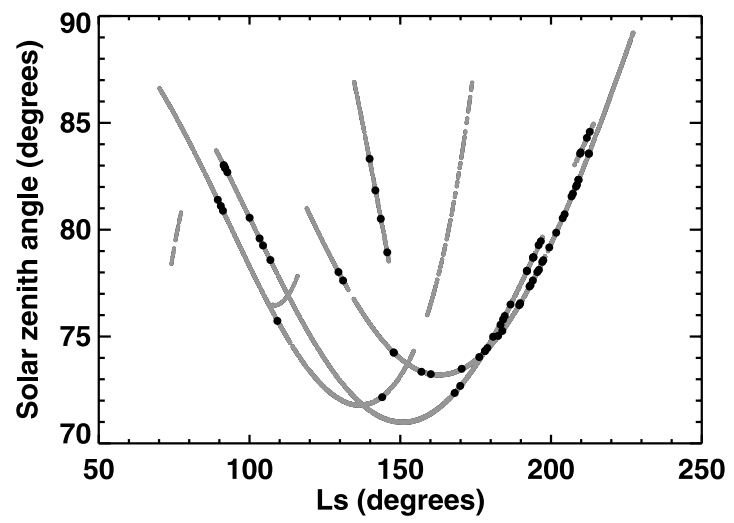

Figure 8. Distribution of all MGS profiles in $L_{s}$ and SZA (grey dots). Profiles containing meteoric layers are shown as black dots. 


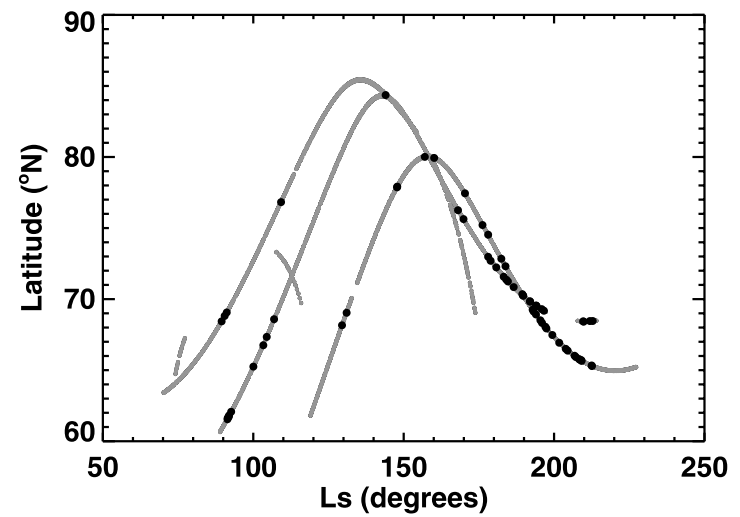

Figure 9. Distribution of all MGS profiles from the northern hemisphere in $L_{s}$ and latitude (grey dots).

other possible ionization mechanisms, we conclude that the low-altitude $\mathrm{M}_{M}$ layers found in this work are produced by meteoroid influx. This conclusion justifies the use of the subscript "M" for "meteoric," which was introduced in section 4.

[28] All meteoric layers identified by application of the algorithm in Appendix A must have $N_{M}>10^{10} \mathrm{~m}^{-3}$. It is probable that meteoric layers with $N_{M}<10^{10} \mathrm{~m}^{-3}$ occur on Mars, but such layers are not readily detected by MGS and are therefore not discussed in this paper. In particular, we cannot exclude the possibility that a layer of metallic ions at $90 \mathrm{~km}$ altitude and plasma densities of, for example, $10^{8} \mathrm{~m}^{-3}$ is always present on Mars.

\section{Leading/Trailing Hemisphere Effects on the Occurrence Rate of Meteoric Layers}

[29] Let $\Psi$ be the angle between the velocity vector of Mars and the vector from the center of Mars to the occultation point. The "nose" of Mars, the location on the planet that is most directly exposed to interplanetary dust, has $\Psi=0^{\circ}$. Occultations on the leading (trailing) hemisphere of Mars have $\Psi<90^{\circ}\left(\Psi>90^{\circ}\right)$. The point on the equator where the sun is rising at dawn (setting at dusk) has $\Psi=0^{\circ}\left(\Psi=180^{\circ}\right)$. The north pole, south pole, noon on the equator and midnight on the equator have $\Psi=90^{\circ}$ at the equinoxes and $\Psi$ close to $90^{\circ}$ at all seasons. The 5380 northern hemisphere profiles have $43^{\circ}<\Psi<89^{\circ}$ and the 220 southern hemisphere profiles have $108^{\circ}<\Psi<111^{\circ}$. Less than $1.3 \%$ of profiles at $40^{\circ}<\Psi<50^{\circ}$ contain meteoric layers. This proportion is $0.6 \%$ at $50^{\circ}<\Psi<$ $60^{\circ}, 0.7 \%$ at $60^{\circ}<\Psi<70^{\circ}, 2.3 \%$ at $70^{\circ}<\Psi<80^{\circ}$, and $1.8 \%$ at $80^{\circ}<\Psi<90^{\circ}$. This proportion is $1.8 \%$ at $108^{\circ}<\Psi$ $<111^{\circ}$. Data coverage is insufficient to study leading/ trailing hemispheric differences.

\section{Other Observed Variations in the Occurrence Rate of Meteoric Layers}

[30] The occurrence rate of meteoric layers is not constant. Determination of the factors that control the occurrence rate of meteoric layers is important for discovering what physical processes affect whether a meteoric layer is observed or not. In this section, we investigate the depen- dence of occurrence rate on $L_{s}$, SZA and latitude. We physically interpret the observed dependences in section 9.

[31] Observed occurrence rate varies with $L_{s}$, SZA and latitude. Only $1.4 \%$ of profiles at $80^{\circ}<L_{s}<110^{\circ}$ contain meteoric layers. This proportion is $0.2 \%$ at $110^{\circ}<L_{s}<$ $140^{\circ}, 0.7 \%$ at $140^{\circ}<L_{s}<170^{\circ}, 3.1 \%$ at $170^{\circ}<L_{s}<200^{\circ}$, and $2.8 \%$ at $200^{\circ}<L_{s}<230^{\circ}$. Only $0.6 \%$ of profiles at $70^{\circ}$ $<\mathrm{SZA}<75^{\circ}$ contain meteoric layers. This rises to $1.8 \%$ at $75^{\circ}<\mathrm{SZA}<80^{\circ}$, and to $2.2 \%$ at $80^{\circ}<\mathrm{SZA}<85^{\circ}$, but falls to $<0.3 \%$ at $85^{\circ}<\mathrm{SZA}<90^{\circ}$. Only $0.9 \%$ of profiles between $60^{\circ} \mathrm{N}$ and $65^{\circ} \mathrm{N}$ contain meteoric layers. This proportion is $2.8 \%$ between $65^{\circ} \mathrm{N}$ and $70^{\circ} \mathrm{N}, 1.1 \%$ between $70^{\circ} \mathrm{N}$ and $75^{\circ} \mathrm{N}, 0.7 \%$ between $75^{\circ} \mathrm{N}$ and $80^{\circ} \mathrm{N}, 0.2 \%$ between $80^{\circ} \mathrm{N}$ and $85^{\circ} \mathrm{N}$, and $<0.7 \%$ between $55^{\circ} \mathrm{N}$ and $90^{\circ} \mathrm{N}$. Southern hemisphere profiles only occur between $64^{\circ} \mathrm{S}$ and $70^{\circ} \mathrm{S}$ at $134^{\circ}<L_{s}<146^{\circ}$ in MY 24. Four of 220 $(1.8 \%)$ southern hemisphere profiles and 67 of $5380(1.2 \%)$ northern hemisphere profiles contain meteoric layers. These hemispheric occurrence rates are indistinguishable because of the small number of meteoric layers in the southern hemisphere. There are not enough observations from the southern hemisphere for meaningful further study of hemispheric effects. There is no dependence of occurrence rate on longitude.

[32] The initial impression is that the occurrence rate of meteoric layers depends on $L_{s}$, SZA and latitude, and that the dependence on SZA has a simple functional form, whereas the dependences on $L_{S}$ and latitude do not. Variations in $L_{s}$, SZA and latitude in the MGS RS data set are related because of orbital geometry, so it is possible that the apparent variations in, for example, latitude are actually due to variations in some other parameter. We would like to study occurrence rate as a function of $L_{s}$, SZA and latitude by holding two parameters constant and varying the third, but that is not permitted by currently available data sets. The next best approach is to hold one parameter constant, vary a second, and neglect the third. However, even this approach is restricted by limited data coverage.

[33] Figure 8 shows the distribution of meteoric layers in $L_{s}$ and SZA. We first hold SZA constant. There are many instances when the occurrence rate of meteoric layers at fixed SZA changes as $L_{s}$ changes. One of 734 profiles $(0.1 \%)$ from $72^{\circ}<\mathrm{SZA}<77^{\circ}$ and $100^{\circ}<L_{s}<130^{\circ}$ contain meteoric layers, versus 17 of 814 profiles $(2.1 \%)$ from the same SZA range and $165^{\circ}<L_{s}<195^{\circ}$. None of 73 profiles $(<1.4 \%)$ from $80^{\circ}<\mathrm{SZA}<85^{\circ}$ and $155^{\circ}<L_{s}<175^{\circ}$ contain meteoric layers, versus 14 of 312 profiles $(4.5 \%)$ from the same SZA range and $200^{\circ}<L_{s}<220^{\circ}$. We next hold $L_{s}$ constant. There are some instances when the occurrence rate of meteoric layers at fixed season increases as SZA increases. Three out of $1156(0.3 \%)$ profiles from $80^{\circ}<L_{S}<150^{\circ}$ and $70^{\circ}<\mathrm{SZA}<75^{\circ}$ contain meteoric layers, versus 7 out of $1096(0.6 \%)$ from the same $L_{s}$ range and $75^{\circ}<\mathrm{SZA}<80^{\circ}$, and 12 out of $724(1.7 \%)$ from the same $L_{s}$ range and $80^{\circ}<\mathrm{SZA}<85^{\circ}$. There are few instances when the occurrence rate of meteoric layers at fixed season decreases as SZA increases.

[34] Figure 9 shows the distribution of meteoric layers in $L_{s}$ and latitude. The four profiles with meteoric layers from the southern hemisphere are not shown in Figure 9. We first hold latitude constant. None of 520 profiles $(<0.2 \%)$ from $70^{\circ} \mathrm{N}-77^{\circ} \mathrm{N}$ and $90^{\circ}<L_{s}<140^{\circ}$ contain meteoric layers, 


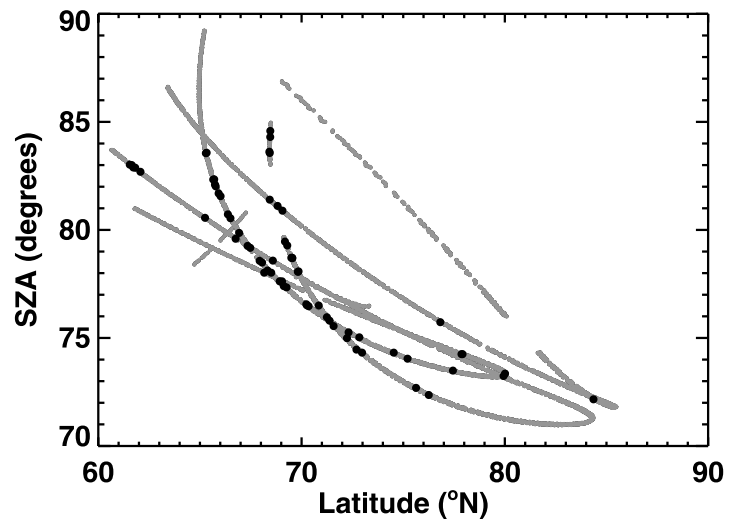

Figure 10. Distribution of all MGS profiles from the northern hemisphere in latitude and SZA (grey dots). Profiles containing meteoric layers are shown as black dots.

versus 13 of 572 profiles (2.3\%) from the same latitudes and $170^{\circ}<L_{s}<200^{\circ}$. Eight of 564 profiles $(1.4 \%)$ from $65^{\circ} \mathrm{N}-$ $70^{\circ} \mathrm{N}$ and $80^{\circ}<L_{s}<130^{\circ}$ contain meteoric layers, versus 26 of 436 profiles $(6.0 \%)$ from the same latitudes and $180^{\circ}<L_{s}$ $<230^{\circ}$. We next hold $L_{s}$ constant. Six of 280 profiles $(2.1 \%)$ from $90^{\circ}<L_{s}<120^{\circ}$ and $65^{\circ} \mathrm{N}-70^{\circ} \mathrm{N}$ contain meteoric layers, versus none of 409 profiles $(<0.2 \%)$ from the same season and $70^{\circ} \mathrm{N}-75^{\circ} \mathrm{N}$. Two of 161 profiles $(1.2 \%)$ from $120^{\circ}<L_{s}<140^{\circ}$ and $65^{\circ} \mathrm{N}-70^{\circ} \mathrm{N}$ contain meteoric layers, versus none of 767 profiles $(<0.1 \%)$ from the same season and $70^{\circ} \mathrm{N}-90^{\circ} \mathrm{N}$.

[35] Figure 10 shows the distribution of meteoric layers in latitude and SZA. The four profiles with meteoric layers from the southern hemisphere are not shown in Figure 10. We first hold SZA constant. Twenty-one of 601 profiles (3.5\%) from $75^{\circ}<\mathrm{SZA}<80^{\circ}$ and $65^{\circ} \mathrm{N}-70^{\circ} \mathrm{N}$ contain meteoric layers, versus 9 of $834(1.1 \%)$ from the same SZA range and $70^{\circ} \mathrm{N}-75^{\circ} \mathrm{N}$, and 1 of $282(0.4 \%)$ from the same SZA range and $75^{\circ} \mathrm{N}-80^{\circ} \mathrm{N}$. Four of 240 profiles $(1.7 \%)$ from $70^{\circ}<\mathrm{SZA}<75^{\circ}$ and $70^{\circ} \mathrm{N}-75^{\circ} \mathrm{N}$ contain meteoric layers, versus 7 of $915(0.8 \%)$ from the same SZA range and $75^{\circ} \mathrm{N}-80^{\circ} \mathrm{N}$, and 2 of $934(0.2 \%)$ from the same SZA range and $80^{\circ} \mathrm{N}-85^{\circ} \mathrm{N}$. There are no comparable instances of the occurrence rate varying significantly if SZA is changed as latitude is held constant.

[36] In summary, the occurrence rate can vary by a factor of ten if latitude is held constant, but $L_{s}$ is varied, and by a factor of twenty if SZA is held constant, but $L_{s}$ is varied. The occurrence rate can vary by a factor of ten if $L_{s}$ is held constant, but latitude is varied, and by a factor of almost ten if SZA is held constant, but latitude is varied. The occurrence rate can vary by a factor of three if $L_{S}$ is held constant, but SZA is varied, although the occurrence rate varies little if latitude is held constant, but SZA is varied.

\section{Interpretation of Variations in Occurrence Rate}

[37] Limited data coverage and correlations between $L_{s}$, SZA and latitude mean that multiple interpretations of observed variations in occurrence rate can be supported by the results of section 8 . Seasonal variations in either meteoroid influx or atmospheric processes that affect mete- oric layer formation may cause $L_{s}$ to affect occurrence rate. Variations in production of ions by photoionization of meteoric atoms or common atmospheric neutrals may cause SZA to affect occurrence rate. Variations in neutral atmospheric properties may cause latitude to affect occurrence rate. Here we outline specific mechanisms by which $L_{s}$, SZA and latitude might affect the occurrence rate.

[38] One possible explanation for the increase in occurrence rate with increasing SZA is based upon the obscuration of meteoric layers by the background ionosphere. The vertical structure of the background ionosphere is very sensitive to SZA. The typical altitude of the lowest data point in an MGS electron density profile increases from $90 \mathrm{~km}$ at $\mathrm{SZA}=72^{\circ}$ to $105 \mathrm{~km}$ at SZA $=87^{\circ}$. The value of $z_{p k}$ similarly increases from $135 \mathrm{~km}$ to $150 \mathrm{~km}$. The vertical structure of the neutral atmosphere is much less sensitive to SZA, and so the deposition of meteoric atoms is also relatively insensitive to SZA. If $z_{M}$ does not vary strongly with SZA (section 11), then meteoric layers will become easier to detect as SZA increases and the obscuring background ionosphere shifts upward. The apparent trend in occurrence rate with SZA changes at $\mathrm{SZA}=85^{\circ}$, yet the Martian ionosphere is sunlit at SZA $<103^{\circ}$. We have not developed any hypotheses to explain this change near the terminator.

[39] One possible explanation for dependence of occurrence rate on $L_{s}$ is variation in meteoroid influx. Meteoroid entry speed, size distribution and number density can vary as Mars orbits the Sun. Meteor showers are a well-known example of this variation, although the properties of the sporadic meteoroid flux at Earth also exhibit seasonal variations [e.g., Campbell-Brown and Jones, 2006]. However, evidence that the properties of terrestrial meteoric layers vary during meteor showers is weak, despite predictions of significant variations [Grebowsky et al., 1998; McNeil et al., 2001; Grebowsky and Aikin, 2002]. Withers et al. (submitted manuscript, 2008) investigate the hypothesis that Martian meteoric layers are affected by meteor showers [Christou et al., 2007; Withers et al., 2007]. The distribution of meteoric layers throughout the Mars year is shown in Figure 11 following calculations outlined in Appendix C. It illustrates that meteoric layers are not

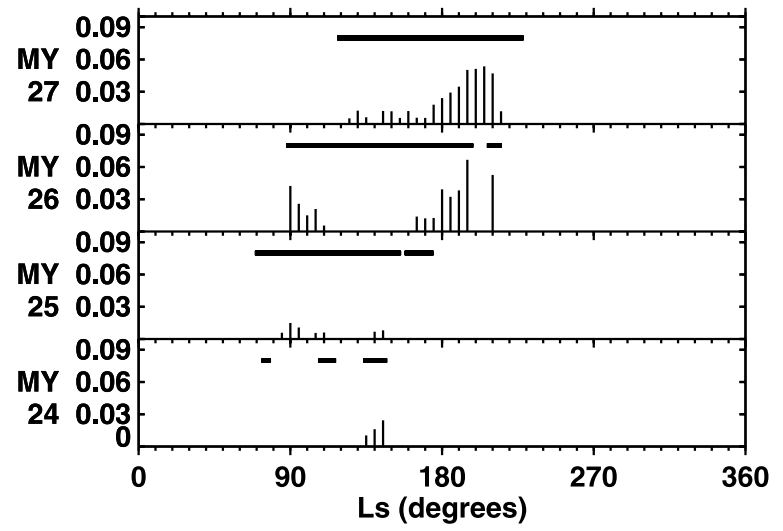

Figure 11. The seasonal distribution of the occurrence rate of meteoric layers, $R_{X, Y}$, for Mars years 24-27 (Appendix C). Values of $R_{X, Y}$ are shown as vertical lines. Horizontal lines show data coverage for each Mars year (Table 1). 


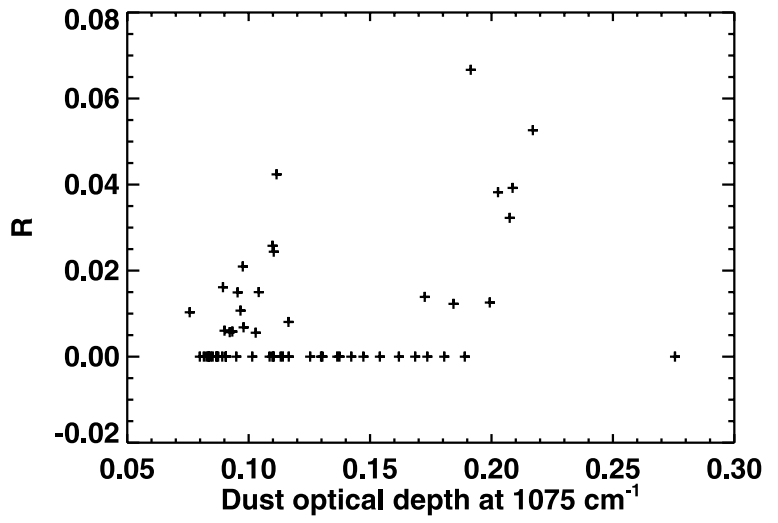

Figure 12. Occurrence rate, $R$, as a function of dust opacity.

distributed randomly nor uniformly throughout the Mars year.

[40] A second possible explanation for dependence of occurrence rate on $L_{s}$, which is also a possible explanation for dependence of occurrence rate on latitude, is atmospheric processes that affect meteoric layer formation. For example, waves in the terrestrial atmosphere play an important role in the formation of meteoric layers. Atmospheric processes vary with both $L_{s}$ and latitude, although it should be noted that these ionospheric observations are completely dominated by observations poleward of $60^{\circ} \mathrm{N}$, so the only relevant atmospheric processes are those affecting the north polar region. However, the mechanisms by which atmospheric dynamics are thought to affect the properties of terrestrial meteoric layers depend on the presence of a strong and global magnetic field [Carter and Forbes, 1999; McNeil et al., 2002]. The Martian magnetic environment is very different from Earth's. In particular, crustal magnetic fields are exceptionally weak poleward of $60^{\circ} \mathrm{N}$ [Connerney et al., 2001]. Withers et al. (submitted manuscript, 2008) evaluate the strengths and weaknesses of analogies between meteoric layers on Earth and Mars.

[41] If the effects of latitude on occurrence rate are negligible because of differences between the Martian and terrestrial magnetic fields, then a possible interpretation of the results of section 8 is that $L_{s}$ has a strong effect on occurrence rate, SZA has a weaker effect on occurrence rate, and the apparent effects of latitude are merely aliased effects of $L_{s}$ and SZA.

\section{Dust Storms and the Occurrence Rate of Meteoric Layers}

[42] Forty-nine of the 71 meteoric layer observations occur at $155^{\circ}<L_{s}<215^{\circ}$, a season when the atmosphere changes from the cool and dust-free aphelion season to the warm and dusty perihelion season [Smith, 2008]. In this section, we investigate whether meteoric layer occurrence rate is influenced by atmospheric dust opacity. Figure 12 plots the occurrence rate of meteoric layers, which is defined quantitatively in Appendix C, against globally averaged dust opacity. Dust opacities were measured by the MGS Thermal Emission Spectrometer (TES) [Smith, 2008, and references therein] and provided to us by $\mathrm{M}$. Smith (personal communication, 2007). Dust opacity varies by a factor of three within the subset of intervals in which no meteoric layers were observed $(R=0)$. Nonzero occurrence rates are clustered around two different opacities, 0.1 and 0.2 , and the many intervals for which dust opacity is $\approx 0.15$ contain no meteoric layers $(R=0)$. The correlation coefficient for occurrence rate and dust opacity is 0.4 , and the first impression is that occurrence rate and dust opacity may be related. Does this correlation indicate a causal relationship or a mere coincidence? Figure 13 shows occurrence rate and globally averaged dust opacity versus $L_{s}$. Consider data from MY $26\left(90^{\circ}<L_{s}<210^{\circ}\right.$ in Figure 11 or $810^{\circ}<L_{s}<930^{\circ}$ in Figure 13). Dust opacity increases monotonically during this interval, but occurrence rate is nonzero, then zero, then nonzero again. The hypothesis that meteoric layer occurrence rate is determined by atmospheric dust opacity cannot explain this seasonal minimum in occurrence rate in MY 26. The most likely explanation is that the apparent seasonal cycle in occurrence rate, which is inferred from MGS data that span only half of a Mars year, is coincidentally similar to the seasonal cycle in dust opacity. MEX observations of meteoric layers do not show correlations between occurrence rate and dust opacity (Withers et al., submitted manuscript, 2008). Although atmospheric dustiness does affect the ionosphere, these effects are limited to a vertical translation of the ionosphere that tracks changes in pressure levels [Hantsch and Bauer, 1990; Wang and Nielsen, 2003]. There is no obvious reason why this should affect the occurrence rate of observable meteoric layers.

\section{Observed Correlations Involving Physical Characteristics}

[43] The characteristics of meteoric layers are controlled by basic physical processes. Studies of relationships between these observable characteristics and other atmospheric or observational properties, such as SZA or scale height, are important for elucidating the operation of these physical processes under Martian conditions. Here we investigate whether $z_{M}, N_{M}$ and $L_{M}$ are correlated with any other parameters.

[44] The few previous publications that have reported theoretical simulations of Martian meteoric layers did not

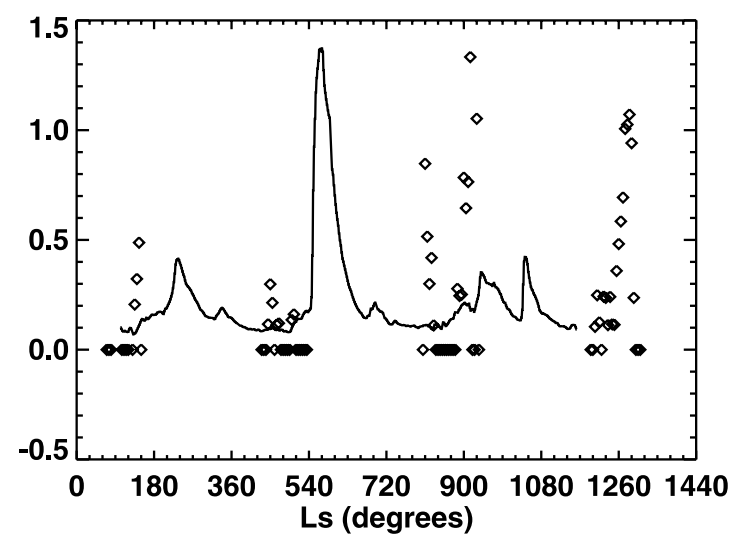

Figure 13. Dust opacity (solid line) as a function of season. $L_{s}=0^{\circ}\left(360^{\circ}, 720^{\circ}\right.$, and $\left.1080^{\circ}\right)$ corresponds to the start of MY $24(25,26$, and 27). Diamonds show $20 \times R$. 
Table 2. Correlation Coefficients Involving the Physical Characteristics of Meteoric Layers ${ }^{\mathrm{a}}$

\begin{tabular}{|c|c|c|}
\hline First Variable & Second Variable & $r$ \\
\hline$z_{M}$ & $L_{M}$ & 0.40 \\
\hline$z_{M}$ & $N_{M}$ & 0.34 \\
\hline$L_{M}$ & $N_{M}$ & 0.31 \\
\hline$z_{M}$ & $L_{s}$ & 0.02 \\
\hline$N_{M}$ & $L_{s}$ & 0.04 \\
\hline$z_{M}$ & $\mathrm{SSL}^{\mathrm{b}}$ & -0.01 \\
\hline$N_{M}$ & $\mathrm{SSL}^{\mathrm{b}}$ & -0.03 \\
\hline$z_{M}$ & Latitude $^{c}$ & -0.07 \\
\hline$N_{M}$ & Latitude $^{c}$ & 0.05 \\
\hline$z_{M}$ & Latitude $^{\mathrm{d}}$ & 0.09 \\
\hline$N_{M}$ & Latitude $^{\mathrm{d}}$ & 0.17 \\
\hline$z_{M}$ & LST & 0.04 \\
\hline$N_{M}$ & LST & 0.06 \\
\hline$z_{M}$ & longitude & 0.07 \\
\hline$N_{M}$ & longitude & 0.15 \\
\hline$z_{M}$ & $\mathrm{~F}_{10.7} \mathrm{e}^{-}$ & 0.19 \\
\hline$N_{M}$ & $\mathrm{~F}_{10.7} \mathrm{e}^{\mathrm{e}}$ & 0.06 \\
\hline$z_{M}$ & $\mathrm{~F}_{10.7}{ }^{10 .} \mathrm{f}$ & 0.07 \\
\hline$N_{M}$ & $\mathrm{~F}_{10.7}{ }^{\mathrm{f}}$ & 0.01 \\
\hline$z_{M}$ & SZA & -0.01 \\
\hline$N_{M}$ & SZA & -0.17 \\
\hline$z_{M}$ & $C h^{\mathrm{g}}$ & -0.05 \\
\hline$N_{M}$ & $C h^{\mathrm{g}}$ & -0.17 \\
\hline$z_{M}$ & $H_{f i t}{ }^{h}$ & -0.05 \\
\hline$N_{M}$ & $H_{f i t}$ & 0.07 \\
\hline$L_{M}$ & $H_{f i t}{ }^{h}$ & -0.06 \\
\hline$z_{M}$ & TEC $^{\mathrm{i}}$ & -0.07 \\
\hline$N_{M}$ & TEC $^{\mathrm{i}}$ & 0.22 \\
\hline$z_{M}$ & $\tau^{j}$ & -0.08 \\
\hline$N_{M}$ & $\tau^{\mathrm{j}}$ & 0.01 \\
\hline$L_{M}$ & $\tau^{\mathrm{j}}$ & 0.07 \\
\hline$z_{M}^{M}$ & $z_{p k}$ & 0.05 \\
\hline$N_{M}$ & $z_{p k}$ & 0.05 \\
\hline$z_{M}$ & $N_{p k}$ & 0.00 \\
\hline$N_{M}$ & $N_{p k}$ & 0.21 \\
\hline
\end{tabular}

${ }^{\mathrm{a}} L_{s}$, SSL, latitude and LST are all known to affect the neutral atmosphere. $\mathrm{F}_{10.7}, \mathrm{SZA}, H_{f i t}$ and $C h$ are all known to affect the ionosphere. TEC, $\tau, z_{p k}$ and $N_{p k}$ are characteristics of the background ionosphere. Correlation coefficients are calculated for $z_{M}$ and $N_{M}$ in all cases. Correlation coefficients are calculated for $L_{M}$ and other vertical length scales, $H_{f i t}$ and $\tau$.

${ }^{\mathrm{b}}$ Subsolar latitude.

${ }^{\mathrm{c}}$ All data.

${ }^{\mathrm{d}}$ Northern hemisphere data only.

${ }^{\mathrm{e}}$ Value of $\mathrm{F}_{10.7}$ at Mars on day of observation [Withers and Mendillo, 2005].

${ }^{\mathrm{f}}$ Value of $\mathrm{F}_{10.7}$ at Earth on day of observation.

${ }^{\mathrm{g}}$ Geometrical correction factor important in Chapman theory, reduces to 1/cos(SZA) for small SZA [Withers and Mendillo, 2005].

${ }^{\mathrm{h}}$ Defined in section 11 .

${ }^{\mathrm{i}}$ Total electron content, a column density.

${ }^{j}$ Slab thickness, TEC $/ N_{p k}$

make quantitative predictions for whether these three physical characteristics should be correlated with other parameters [Pesnell and Grebowsky, 2000; Molina-Cuberos et al., 2003]. Accordingly, we have no a priori expectations for the values of these correlation coefficients.

[45] Experience with the other layers of the Martian ionosphere, M1 and M2, suggests that strong correlations should be expected. For example, the correlation coefficient for values of $N_{p k}$ and $C h$ from the 71 profiles that contain meteoric layers is -0.75 , where $C h$, a geometrical correction factor important in Chapman theory, reduces to $1 /$ cos(SZA) for small SZA [Withers and Mendillo, 2005]. The corresponding coefficient for $z_{p k}$ and subsolar latitude is -0.62 . Therefore it is plausible that strong correlations might be found that involve the physical characteristics of meteoric layers. Parameters that might affect meteoric layers include parameters known to affect the neutral atmosphere, such as $L_{s}$, subsolar latitude and LST; parameters known to affect the ionosphere, such as $\mathrm{F}_{10.7}, \mathrm{SZA}, H_{\text {fit }}$ and $C h$; characteristics of the background ionosphere, such as total electron content, slab thickness, $z_{p k}$ and $N_{p k}$; and characteristics of meteoroid influx, such as number density, typical size and speed. $H_{f i t}$, an atmospheric scale height, can be found from an observed electron density profile by fitting a Chapman function to the M2 layer [e.g., Withers and Mendillo, 2005]. There are no observations of meteoroid influx characteristics at Mars during the MGS mission, so we cannot test whether physical characteristics of meteoric layers are related to meteoroid influx characteristics. Experience at $1 \mathrm{AU}$ suggests that meteoroid influx characteristics are not constant. This section is therefore restricted to testing whether physical characteristics of meteoric layers are related to parameters known to affect the neutral atmosphere, parameters known to affect the ionosphere, and characteristics of the background ionosphere.

[46] Correlation coefficients, $r$, for many pairs of these variables are shown in Table 2. Absolute values of correlation coefficients of $N_{M}, z_{M}$ and $L_{M}$ with $\Psi$ are $<0.06$ (section 7). Note that the correlation coefficients in Table 2 are independent of uncertainties. The conclusions of this section are not significantly altered by consideration of uncertainties.

[47] No correlation coefficient exceeds 0.4 in absolute value, which illustrates how different the processes that control the meteoric layer are from those that control the M1 and M2 layers [Withers and Mendillo, 2005]. The three strongest correlations, which are all positive, are for the pairs of variables $z_{M}: L_{M}, z_{M}: N_{M}$ and $L_{M}: N_{M}$. The correlation coefficient $r$ exceeds 0.3 in all three cases.

[48] There are several other correlation coefficients in Table 2 whose absolute values exceed 0.15 . The correlation coefficient between $N_{M}$ and latitude (northern hemisphere data only) is 0.17 , although there is no self-evident reason for a positive correlation between these two variables. The correlation coefficient between $z_{M}$ and $\mathrm{F}_{10.7}$ at Mars is 0.19 , yet the correlation coefficient between $N_{M}$ and $\mathrm{F}_{10.7}$ at Mars is only 0.06 . In the M2 layer, $N_{M}$ is positively correlated with $\mathrm{F}_{10.7}$, but $z_{M}$ is uncorrelated with $\mathrm{F}_{10.7}$. The correlation coefficient between $N_{M}$ and SZA is -0.17 , but the correlation coefficient between $z_{M}$ and SZA is only -0.01 . In the M2 layer, $N_{M}$ is negatively correlated with SZA, but $z_{M}$ is positively correlated with SZA. The correlation coefficient between $N_{M}$ and TEC is 0.22 . Since the detection of a lowaltitude meteoric layer always implies the presence of more plasma than usual, this weak positive correlation is not surprising. The correlation coefficient between $N_{M}$ and $N_{p k}$ is 0.21 . We have not investigated correlations that involve properties of the M1 layer, such as its altitude and electron density, because these properties are challenging to determine unambiguously from MGS observations.

\section{Summary of Physical Characteristics and Their Correlations}

[49] The range in $L_{M}$ is very large, $1-27 \mathrm{~km}$. The 10 th and 90th percentiles of $L_{M}$ are $4.2 \mathrm{~km}$ and $16.5 \mathrm{~km}$. The 10th and 90th percentiles of $H_{\text {fit }}$ are $9.5 \mathrm{~km}$ and $15.5 \mathrm{~km} . L_{M}$ 


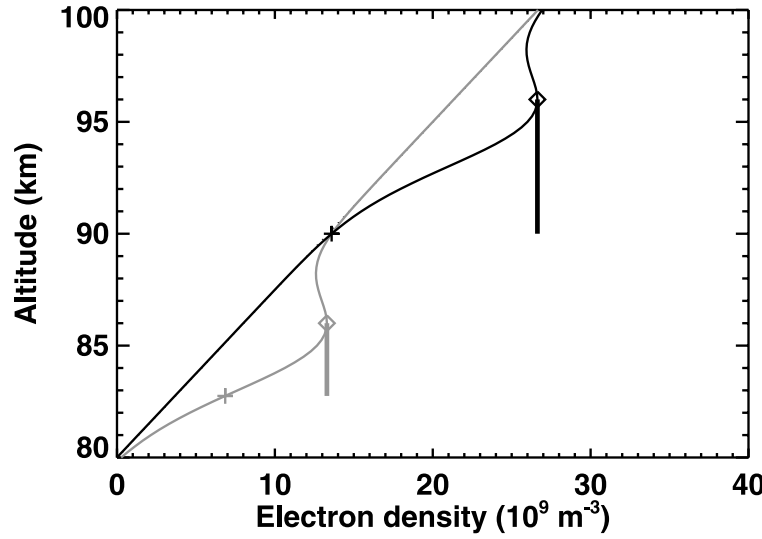

Figure 14. $N_{\text {tot }}$ from the simple conceptual model of section 13. Grey (black) lines and symbols correspond to $z_{0}=85(95) \mathrm{km}$. Values of $N_{\text {tot }}$ are given by solid curved lines, values of $z_{M}$ and $N_{M}$ are indicated by open diamonds, and values of $z_{M}-L_{M} / 2$ and $N_{M} / 2$ are indicated by crosses. Values of $L_{M} / 2$ are shown by the lengths of the solid vertical lines. For $z_{0}=85 \mathrm{~km}, z_{M}=86 \mathrm{~km}, N_{M}=1.3 \times 10^{10}$, and $L_{M}=6.5 \mathrm{~km}$. For $z_{0}=95 \mathrm{~km}, z_{M}=96 \mathrm{~km}, N_{M}=2.7 \times$ $10^{10}$, and $L_{M}=12 \mathrm{~km}$.

cannot be simply related to any atmospheric scale height, because atmospheric scale heights and temperatures do not vary as much as $L_{M}$ does [Bougher et al., 2004, 2006; Withers, 2006]. Also, $L_{M}$ and $H_{f i t}$ are uncorrelated $(r=-0.05$, Table 2).

[50] Pätzold et al. [2005] analyzed 10 meteoric layers using MEX RS data and determined that two pairs of variables, $z_{M}$ :SZA and $z_{M}: L_{M}$, were positively correlated. $z_{M}$ and $N_{M}$ are also positively correlated in their data. Their tabulated "altitude range," a measure of layer width, varies between 11 and $45 \mathrm{~km}$. There is a difference of a factor of four between the MEX RS's minimum and maximum "altitude range" and between the 10th and 90th percentiles of MGS RS's $L_{M}$.

[51] Both the MGS and MEX data sets show that (1) $z_{M}$ and $N_{M}$ are positively correlated, (2) $z_{M}$ and $L_{M}$ are positively correlated, and (3) $L_{M}$ has a large range. The MGS data set shows that (4) $L_{M}$ is not correlated with scale height and (5) $N_{M}$ does not show any dependence on SZA. The MEX data set shows that (6) $z_{M}$ and SZA (and, equivalently, $N_{M}$ and SZA) are positively correlated. The only contradiction concerns the relationship between $N_{M}$ and SZA (points 5 and 6). We cannot resolve this contradiction at present without invoking hard-to-verify mechanisms such as unusual meteoroid influx characteristics for the four MEX observations at large SZA. We proceed by accepting the conclusion drawn from the larger MGS data set.

\section{Interpretation of Correlations}

[52] In order to properly interpret these observations, we must explain the six points identified in section 12 .

[53] Two important mechanisms that are predicted to produce meteoric ions, photoionization of neutral metal atoms and charge exchange between neutral metal atoms and ambient ions, should cause $N_{M}$ to decrease as SZA increases. However, simulations have not yet explicitly investigated the possible dependence of $N_{M}$ on SZA [Pesnell and Grebowsky, 2000; Molina-Cuberos et al., 2003]. No dependence of $N_{M}$ on SZA is found in the MGS observations (point 5). A possible explanation for the lack of dependence of $N_{M}$ on SZA is that the scale of plausible variations of $N_{M}$ with SZA is a factor of $\sim 3$ for MGS observing conditions. This small variation could be overwhelmed by larger variations in solar irradiance. Most ion production at meteoric layer altitudes is caused by X-ray photons. Solar X-ray irradiance varies unpredictably by orders of magnitude on time scales of minutes to years.

[54] The strong relationship between the three physical characteristics of meteoric layers, and the small values of all other correlation coefficients in Table 2, are consistent with the hypothesis that meteoroid influx characteristics control the physical characteristics of meteoric layers, at least for the range of conditions sampled by the MGS RS data set. Another alternative is that the processes that shape meteoric layers are relatively complex, involving interactions between multiple parameters.

[55] A simple conceptual model can be developed for the hypothesis that meteoroid influx characteristics control the physical characteristics of meteoric layers. It is consistent with the remaining observations (points $1-4)$. The model's total electron density, $N_{t o t}$, is the sum of a background component, $N_{b g d}$, and a meteoric component, $N_{\text {extra }}$. $N_{b g d}$ varies linearly with altitude, is 0 at $80 \mathrm{~km}$, and is $4 \times 10^{10} \mathrm{~m}^{-3}$ at $110 \mathrm{~km}$. $N_{\text {extra }}$ has a Gaussian shape:

$$
N_{\text {extra }}=N_{0} \exp \left(\frac{-x_{e}^{2}}{2 s^{2}}\right)
$$

where $N_{0}=6 \times 10^{9} \mathrm{~m}^{-3}, s=2 \mathrm{~km}$ and $x_{e}=z-z_{0}$, where $z_{0}$ is a variable. Figure 14 shows $N_{\text {tot }}$ for two different values of $z_{0}, 85 \mathrm{~km}$ and $95 \mathrm{~km} . N_{M}$ and $L_{M}$ increase as $z_{M}$ increases in the model, just as in the observations. Only one model parameter, $z_{0}$, varies. This is the meteoroid ablation altitude, which is determined by meteoroid entry speed and mass [Pesnell and Grebowsky, 2000; McAuliffe and Christou, 2006; McAuliffe, 2006].

[56] This model does not contain any physical processes and is not intended to provide quantitative predictions. Its main purpose is to illustrate a scenario consistent with the correlations in Table 2. Further work is needed to develop a physics-based model that is consistent with these correlations.

\section{Variability in the Physical Characteristics of Meteoric Layers}

[57] The observed physical characteristics of meteoric layers vary greatly. Published models have not fully explored possible causes of this variability [Pesnell and Grebowsky, 2000; Molina-Cuberos et al., 2003]. Here we consider what factors will affect $N_{M}, z_{M}$ and $L_{M}$.

[58] It is likely that predicted values of $N_{M}$ will vary with SZA, solar X-ray flux, meteoroid flux, meteoroid entry speed and $z_{M}$. Changes in SZA and solar X-ray flux affect 


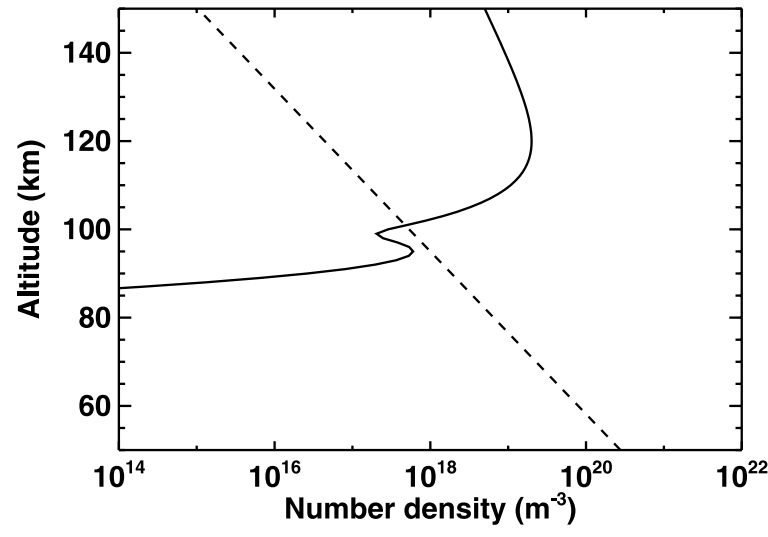

Figure 15. The dashed line shows neutral number density, $n$, from the illustrative model of section 15 . The solid line shows $10^{8} \times$ electron density, $N_{\text {tot }}$, from the illustrative model of section 15 .

the direct photoionization rate of metallic atoms and the number of $\mathrm{O}_{2}^{+}$ions available for charge exchange reactions. Changes in meteoroid flux affect the deposition rate of metallic atoms, which affects the total number density of all metallic species, which affects the number density of metallic ions. Changes in meteoroid entry speed affect the proportion of ablated metallic atoms that are immediately ionized by impact ionization, which affects the number density of metallic ions. Changes in $z_{M}$ affect the optical depth at $z_{M}$, which affects the direct photoionization rate of metallic atoms and the number of $\mathrm{O}_{2}^{+}$ions available for charge exchange reactions. Two of these possible factors were investigated in section 11 and Table 2. Variations in $N_{M}$ with $z_{M}$ were observed, but variations in $N_{M}$ with SZA were not observed.

[59] It is likely that predicted values of $z_{M}$ will vary with meteoroid entry angle, entry speed, size distribution, atmospheric density and atmospheric density scale height. Changes in entry angle affect the altitude at which the mass of atmospheric gases swept aside by a descending meteoroid equals the meteoroid mass, thereby affecting the ablation altitude. Meteoroid mass and speed affect rates of mass loss and descent. Ablation and deceleration are primarily controlled by atmospheric density, so changes in atmospheric density and density scale height affect the altitude at which ablation occurs. One of these possible factors was investigated in section 11 and Table 2. Variations in $z_{M}$ with $H_{f i t}$, the neutral scale height, were not observed.

[60] Important factors for $L_{M}$ are less clear cut. Changes in density scale height, which affect the width of the peak in mass loss rate, should affect $L_{M}$. Changes in poorly known eddy diffusion coefficients, which represent the effects of dynamical mixing processes, affect how the vertical profile of mass loss rate is related to the vertical profile of total number density of all metallic species, and also affect $L_{M}$. This can be seen in the work by Pesnell and Grebowsky [2000, Figure 7]. Note that changes in the eddy diffusion coefficient also affect $N_{M}$ significantly. One of these possible factors was investigated in section 11 and Table 2 .
Variations in $L_{M}$ with $H_{f i t}$, the neutral scale height, were not observed.

[61] There is a clear need for theoretical modeling efforts that investigate variability in the physical characteristics of meteoric layers.

\section{Lifetime of Meteoric Plasma}

[62] When metallic ions are produced from meteoric material, they are produced as atomic ions. Although Pesnell and Grebowsky [2000] and [Molina-Cuberos et $a l ., 2003$ ] do not explicitly state a time scale for loss of metallic ions, an upper limit can be estimated [Rishbeth and Garriott, 1969].

[63] The rate constant for the radiative recombination of atomic metallic ions via reactions such as $\mathrm{Mg}^{+}+e \rightarrow \mathrm{Mg}+h v$ is $k_{1}=4 \times 10^{-12} \mathrm{~cm}^{3} \mathrm{~s}^{-1}$ [Pesnell and Grebowsky, 2000]. Thus $d N_{M^{+}} / d t=-k_{1} N_{M^{+}} N_{e}$, where $t$ is time, $N_{M^{+}}$is the number density of atomic metallic ions and $N_{e}$ is the electron number density. Consequently, $\tau_{M^{+}, r r}$, the time scale for the loss of atomic metallic ions by radiative recombination (rr), equals $1 / k_{1} N_{e}$. This time scale is 290 days for $N_{e}=10^{10} \mathrm{~m}^{-3}$, a typical meteoric layer electron density.

[64] The rate constant for formation of molecular metallic ions from atomic metallic ions via three-body reactions, such as $\mathrm{Mg}^{+}+2 \mathrm{CO}_{2} \rightarrow \mathrm{Mg}^{+} \cdot \mathrm{CO}_{2}+\mathrm{CO}_{2}$, is $k_{2}=10^{-30}$ $\mathrm{cm}^{6} \mathrm{~s}^{-1}$ [Pesnell and Grebowsky, 2000]. Thus $d N_{M^{+}} / d t=$ $-k_{2} N_{M+} n^{2}$, where $n$ is the neutral number density. Consequently, $\tau_{M+, m m}$, the time scale for the loss of atomic metallic ions by conversion into molecular metallic $(\mathrm{mm})$ ions, equals $1 / k_{2} n^{2}$. This time scale is 12 days for $n=10^{18}$ $\mathrm{m}^{-3}$, which occurs around $95 \mathrm{~km}$ [Pesnell and Grebowsky, 2000]. The rate constant for the dissociative recombination of molecular metallic ions, such as $\mathrm{Mg}^{+} \cdot \mathrm{CO}_{2}+e \rightarrow \mathrm{Mg}+$ $\mathrm{CO}_{2}$, is $k_{3}=3 \times 10^{-7} \mathrm{~cm}^{3} \mathrm{~s}^{-1}$ [Pesnell and Grebowsky, 2000]. Consequently, $\tau_{M X+, d r}$, the time scale for the loss of molecular metallic ions by dissociative recombination (dr), equals $1 / k_{3} N_{e}$. This time scale is 6 minutes for $N_{e}=10^{10}$ $\mathrm{m}^{-3}$, a typical meteoric layer electron density. $\tau_{M X+, d r}$ is always less than $\tau_{M+, r r}$ because $k_{3}>k_{1}$.

[65] These time scales can be explored in an illustrative model of a neutral atmosphere and ionosphere. The number density, $n$, of the neutral atmosphere is given by:

$$
n=n_{r} \exp \left(\frac{-\left(z-z_{r}\right)}{H_{r}}\right)
$$

where $n_{r}=10^{18} \mathrm{~m}^{-3}, z$ is altitude, $z_{r}=95 \mathrm{~km}$ and $H_{r}=8 \mathrm{~km}$ [Pesnell and Grebowsky, 2000]. The ionospheric electron density, $N_{t o t}$, is the sum of two components, a background component, $N_{b g d}$, and a meteoric component, $N_{\text {extra }} . N_{b g d}$ is given by:

$$
N_{b g d}=N_{c}\left[\exp \left(1-x_{c}-\exp \left(-x_{c}\right)\right)\right]^{0.5}
$$

where $N_{c}=2 \times 10^{11} \mathrm{~m}^{-3}, x_{c}=\left(z-z_{c}\right) / H_{c}, z_{c}=120 \mathrm{~km}$ and $H_{c}=H_{r}$ [Bauer and Hantsch, 1989; Withers, 2008]. $N_{\text {extra }}$ is given by equation (1). $N_{\text {tot }}$ and $n$ are shown in Figure 15. The time scales $\tau_{M+, r r}, \tau_{M+, m m}$ and $\tau_{M X^{+}, d r}$ are shown in 


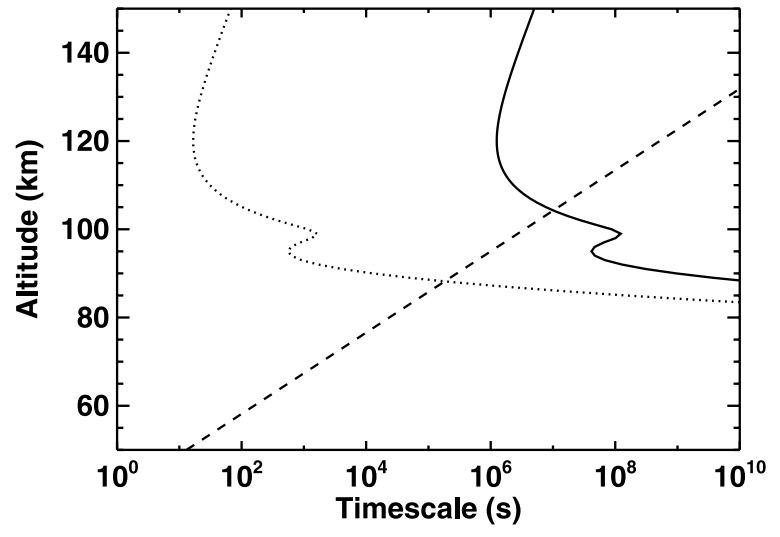

Figure 16. The solid line shows $\tau_{M X+, r r}$, the dashed line shows $\tau_{M+, m m}$, and the dotted line shows $\tau_{M X+, d r}$ from the illustrative model of section 15 .

Figure 16. For $z<90 \mathrm{~km}, \tau_{M^{+}, m m}<\tau_{M X+, d r}$, the fastest loss mechanism is conversion into molecular ions followed by dissociative recombination, and the rate-limiting step is dissociative recombination. For $90 \mathrm{~km}<z<105 \mathrm{~km}$, $\tau_{M X+, d r}<\tau_{M+, m m}<\tau_{M X+, r r}$, the fastest loss mechanism is conversion into molecular ions followed by dissociative recombination, and the rate-limiting step is conversion into molecular ions. For $105 \mathrm{~km}<z, \tau_{M^{+}, r r}<\tau_{M^{+}, m m}$, the fastest loss mechanism is radiative recombination. $\tau_{M^{+}, m m}$ is 3 days at $90 \mathrm{~km}$ and 140 days at $105 \mathrm{~km}$.

[66] At meteoric layer altitudes, the time scale for loss of metallic ions is set by the slow conversion of atomic metallic ions into molecular metallic ions. The estimated lifetime of 12 days at $95 \mathrm{~km}$ is an upper limit because it does not consider all possible reaction pathways nor plasma transport. This time scale increases by a factor of $e^{2}$, or almost an order of magnitude, for every scale height by which altitude increases. This suggests that meteoric layers can be detected in the nightside ionosphere and that changes in the occurrence rate or electron density of meteoric layers due to brief meteor showers can persist for days after the end of the shower. It also supports the hypothesis of Pätzold et al. [2005] that a meteoric layer observed at the same latitude and longitude on successive days is the same plasma layer, not a series of short-lived plasma layers. Meteoric layers should survive the Martian night.

\section{Conclusions}

[67] Low-altitude layers of ionospheric plasma have been found in 71 of 5600 MGS electron density profiles. These layers, which we label $\mathrm{M}_{M}$, are clearly distinct from the M1 and M2 layers produced by the photoionization of $\mathrm{CO}_{2}$ by solar X-ray and EUV photons, respectively. The mean altitude of these layers is $91.7 \pm 4.8 \mathrm{~km}$. The mean peak electron density in these layers is $(1.33 \pm 0.25) \times 10^{10} \mathrm{~m}^{-3}$. The mean width of these layers is $10.3 \pm 5.2 \mathrm{~km}$. It is important to determine the mechanism responsible for these layers. Two models have predicted that meteoroid influx should produce low-altitude plasma layers. Predicted meteoric layer altitudes are within one scale height of the mean observed altitude. Predicted meteoric layer electron densities bracket the mean observed electron density. Predicted meteoric layer widths are within a factor of two of the mean observed width. Other possible causes of low-altitude ionization include the solar wind, solar flares and solar energetic particles, but none of these have been shown to produce plasma layers with the observed altitude, electron density and width. Several profiles contain multiple lowaltitude layers, which are common in terrestrial meteoric layers. We attribute the origin of the observed low-altitude plasma layers to meteoroid influx.

[68] The observed occurrence rate of meteoric layers depends on $L_{s}$, SZA and season, although detailed studies are impeded by limited data coverage and correlations between $L_{s}$, SZA and season. Variations with $L_{s}$ are particularly strong and the dependence of occurrence rate on season is examined in more detail by Withers et al. (submitted manuscript, 2008). The occurrence rate of meteoric layers is significantly greater in MEX observations than in MGS observations [Pätzold et al., 2005; Withers et al., submitted manuscript, 2008]. Uncertainties in electron density are typically $3 \times 10^{9} \mathrm{~m}^{-3}$ in MGS observations and $1 \times 10^{9} \mathrm{~m}^{-3}$ in MEX observations. The different measurement uncertainties are likely to be at least partially responsible for this difference in occurrence rate.

[69] The width $\left(L_{M}\right)$, altitude $\left(z_{M}\right)$, and electron density $\left(N_{M}\right)$ of each meteoric layer have been found. There are remarkably few correlations between these physical characteristics of meteoric layers and atmospheric or observational properties, such as scale height, SZA and solar flux. Many strong correlations would be found if the M2 layer were analyzed instead of the meteoric layer. The three strongest correlations, which are all positive, are for pairs $z_{M}: L_{M}$, $z_{M}: N_{M}$ and $L_{M}: N_{M}$. None of these correlation coefficients exceeds 0.4 . Variations in the width of the meteoric layer, which are about a factor of four, are much greater than the variations in any relevant scale height. The width of the meteoric layer is not correlated with the neutral density scale height at the M2 layer. There is one contradiction between studies of the physical characteristics of meteoric layers using MGS and MEX data sets: $N_{M}$ and SZA are positively correlated in ten MEX observations, but are uncorrelated in 71 MGS observations.

[70] A simple conceptual model, based on the hypothesis that meteoroid influx characteristics control the physical characteristics of meteoric layers, has been developed to illustrate the need for more realistic simulations of variations in the physical characteristics of meteoric layers. It is consistent with the observed correlations between $z_{M}, N_{M}$ and $L_{M}$. Some possible causes of these variations have been suggested to guide future numerical simulations that use realistic physics-based models. Continued interpretation of these observations will be improved by such modeling work.

[71] The photochemical lifetime of meteoric plasma is long, on the order of days, which suggests that meteoric layers should survive the Martian night and that the effects 


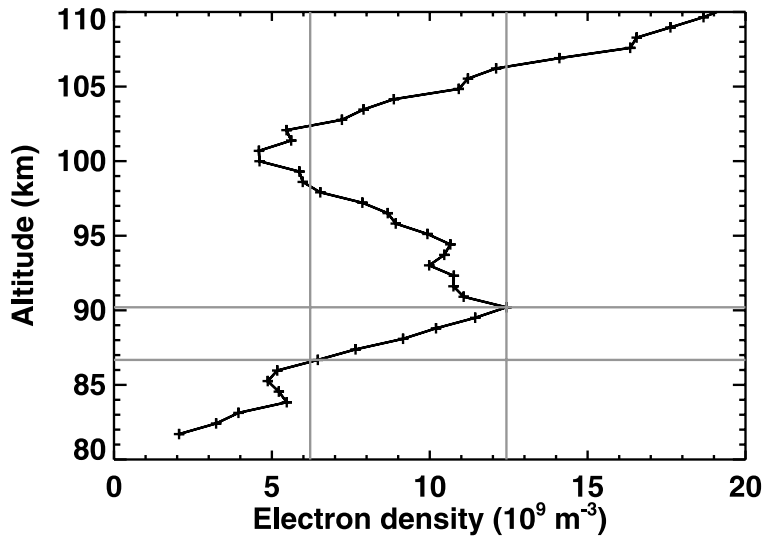

Figure B1. Portion of profile 5127R00A.EDS (Figure 3). Data points are shown as black crosses and joined by black lines. Two vertical grey lines show $N=N_{M}$ (right line) and $N=N_{M} / 2$ (left line). Two horizontal grey lines show $z=z_{M}$ (top line) and $z=z_{Y}=z_{M}-L_{M} / 2$ (bottom line).

of brief meteor showers will persist. However, the lifetime of meteoric plasma might be reduced by transport processes.

\section{Appendix A: Algorithm to Identify Low-Altitude Plasma Layers}

[72] First, the quantity $X_{i, p}$ is calculated at each altitude level $i$ in each profile $p$ as:

$$
X_{i, p}=2 \frac{N_{i}-N_{j}}{N_{i}+N_{j}}
$$

where $z_{i}+D=z_{j}$ and $D=5 \mathrm{~km} . z_{i}$ is below $z_{j}$. Second, $X_{i, p}$ is set equal to zero if $N_{i}<\sigma_{i}, N_{j}<\sigma_{j}, N_{i}<10^{10} \mathrm{~m}^{-3}$ or $z_{i}>$ $95 \mathrm{~km}$, where $\sigma$ is the uncertainty in $N$. The threshold altitude of $95 \mathrm{~km}$ is used to ensure that this algorithm does not detect the M1 layer produced by solar X rays at $\sim 110 \mathrm{~km}$. Third, $Y_{p}$ is defined as the maximum value of $X_{i, p}$ over all values of $i$. In most profiles, $d N / d z>0$ below $100 \mathrm{~km}$. That is, $N_{i}<N_{j}$ and $X_{i, p}<0$. If a low-altitude layer is present at low altitudes in profile $p$, then $d N / d z<0$ on the topside of the layer, some values of $X_{i, p}$ are positive, and $Y_{p}$ is positive. Profile $p$ is declared to contain a low-altitude plasma layer if $Y_{p}>0$.

\section{Appendix B: Determination of the Physical Characteristics of Low-Altitude Plasma Layers}

[73] We define $z_{X}$ as the altitude at which $X_{i, p}$ is maximized. We define $N_{M}$ as the maximum electron density below $z_{X}+D$ (see Appendix A), and $z_{M}$ as the altitude at which $N=N_{M} \cdot z_{Y}$ is defined as the altitude below $z_{M}$ at which $N=N_{M} / 2$, and $L_{M}$ is defined by $L_{M} / 2=z_{M}-z_{Y}$ (Figure B1). We do not consider the topside of the lowaltitude layer when calculating $L_{M}$ because $N$ often remains greater than $N_{M} / 2$ until far above the M2 layer. In 4 of the 71 profiles that contain low-altitude layers, $N_{M} / 2$ is smaller than the uncertainty in $N$, and hence smaller than the smallest value of $N$, which makes it impossible to determine $L_{M}$. These four profiles are not considered in analyses involving $L_{M}$. Note that this procedure provides one value of $z_{M}, N_{M}$ and $L_{M}$ per profile, even if the profile contains multiple low-altitude layers (section 6). This ensures consistency and, since there are few profiles with multiple lowaltitude layers, will not adversely affect the results.

[74] We define $\sigma_{N m}$, the uncertainty in $N_{M}$, as the uncertainty in $N$ at $z_{M}$. We define $\sigma_{z m}$, the uncertainty in $z_{M}$, as half the separation between the data points immediately above and below $z_{M}$. We define $\sigma_{L m}$, the uncertainty in $L_{M}$, as $2 \sigma_{z m}$.

\section{Appendix C: Seasonal Distribution of Meteoric Layer Observations}

[75] The number of meteoric layer detections, $M_{X, Y}$ is defined as the number of meteoric layer detections that satisfy $X-5^{\circ}<L_{s}<X+5^{\circ}$, Mars year Y. $X=5^{\circ}, 10^{\circ}, 15^{\circ}$, ... The number of available profiles, $N_{X, Y}$, is similarly defined as the number of ionospheric profiles that satisfy these criteria. The relative occurrence of the meteoric layer, $R_{X, Y}$ is defined as $M_{X, Y} / N_{X, Y} R_{X, Y}$ is undefined if $N_{X, Y}=0$. Coverage of the data set is listed in Table 1 and illustrated in Figure 11.

[76] Acknowledgments. We acknowledge helpful discussions with Martin Pätzold and Silvia Tellmann.

[77] Wolfgang Baumjohann thanks Olivier G. Witasse and Joseph Grebowsky for their assistance in evaluating this paper.

\section{References}

Aikin, A. C., and W. C. Maguire (2005), Detection in the infrared of $\mathrm{Mg}^{+}$. $\mathrm{CO}_{2}$ ion produced via meteoritic material in the Martian atmosphere, paper 33.37 presented at DPS Meeting, Am. Astron. Soc., Cambridge, U. K.

Bauer, S. J., and M. H. Hantsch (1989), Solar cycle variation of the upper atmosphere temperature of Mars, Geophys. Res. Lett., 16, 373-376.

Bougher, S. W., S. Engel, D. P. Hinson, and J. M. Forbes (2001), Mars Global Surveyor Radio Science electron density profiles: Neutral atmosphere implications, Geophys. Res. Lett., 28, 3091-3094, doi:10.1029/ 2001GL012884

Bougher, S. W., S. Engel, D. P. Hinson, and J. R. Murphy (2004), MGS Radio Science electron density profiles: Interannual variability and implications for the Martian neutral atmosphere, J. Geophys. Res., 109, E03010, doi:10.1029/2003JE002154.

Bougher, S. W., J. M. Bell, J. R. Murphy, M. A. Lopez-Valverde, and P. G. Withers (2006), Polar warming in the Mars thermosphere: Seasonal variations owing to changing insolation and dust distributions, Geophys. Res. Lett., 33, L02203, doi:10.1029/2005GL024059.

Butler, D. M., and J. W. Chamberlain (1976), Venus' night side ionosphere: Its origin and maintenance, J. Geophys. Res., 81, 4757-4760.

Campbell-Brown, M. D., and J. Jones (2006), Annual variation of sporadic radar meteor rates, Mon. Not. R. Astron. Soc., 367, 709-716, doi:10.1111/j.1365-2966.2005.09974.x.

Carter, L. N., and J. M. Forbes (1999), Global transport and localized layering of metallic ions in the upper atmosphere, Ann. Geophys., 17, 190-209.

Chen, R. H., T. E. Cravens, and A. F. Nagy (1978), The Martian ionosphere in light of the Viking observations, J. Geophys. Res., 83, 3871-3876.

Christou, A. A., J. Vaubaillon, and P. Withers (2007), The dust trail complex of 79P/du Toit-Hartley and meteor outbursts at Mars, Astron. Astrophys., 471, 321-329.

Clancy, R. T., B. J. Sandor, M. J. Wolff, P. R. Christensen, M. D. Smith, J. C. Pearl, B. J. Conrath, and R. J. Wilson (2000), An intercomparison of ground-based millimeter, MGS TES, and Viking atmospheric temperature measurements: Seasonal and interannual variability of temperatures and dust loading in the global Mars atmosphere, J. Geophys. Res., 105, 9553-9572, doi:10.1029/1999JE001089.

Connerney, J. E. P., M. H. Acuña, P. J. Wasilewski, G. Kletetschka, N. F. Ness, H. Rème, R. P. Lin, and D. L. Mitchell (2001), The global magnetic field of Mars and implications for crustal evolution, Geophys. Res. Lett., 28, 4015-4018, doi:10.1029/2001GL013619.

Duru, F., D. A. Gurnett, D. D. Morgan, R. Modolo, A. F. Nagy, and D. Najib (2008), Electron densities in the upper ionosphere of Mars from the excitation of electron plasma oscillations, J. Geophys. Res. 113, A07302, doi:10.1029/2008JA013073 
Espley, J. R., W. M. Farrell, D. A. Brain, D. D. Morgan, B. Cantor, J. J. Plaut, M. H. Acuña, and G. Picardi (2007), Absorption of MARSIS radar signals: Solar energetic particles and the daytime ionosphere, Geophys. Res. Lett., 34, L09101, doi:10.1029/2006GL028829.

Fjeldbo, G., B. Seidel, D. Sweetnam, and T. Howard (1975), The Mariner 10 radio occultation measurements of the ionosphere of Venus, J. Atmos. Sci., 32, 1232-1236.

Fox, J. L. (2004a), Advances in the aeronomy of Venus and Mars, Adv. Space Res., 33, 132-139, doi:10.1016/j.asr.2003.08.014.

Fox, J. L. (2004b), Response of the Martian thermosphere/ionosphere to enhanced fluxes of solar soft X rays, J. Geophys. Res., 109, A11310, doi:10.1029/2004JA010380.

Fox, J. L., and A. J. Kliore (1997), Ionosphere: Solar cycle variations, in Venus II, pp. 161-188, Univ. of Ariz. Press, Tucson.

Fox, J. L., P. Zhou, and S. W. Bougher (1996), The Martian thermosphere/ ionosphere at high and low solar activities, Adv. Space Res., 17(11), $203-$ 218

Grebowsky, J. M., and A. C. Aikin (2002), In situ measurements of meteoric ions, in Meteors in the Earth's Atmosphere, pp. 189-214, Cambridge Univ. Press, New York.

Grebowsky, J. M., R. A. Goldberg, and W. D. Pesnell (1998), Do meteor showers significantly perturb the ionosphere?, J. Atmos. Sol. Terr. Phys., $60,607-615$.

Gurnett, D. A., et al. (2005), Radar soundings of the ionosphere of Mars, Science, 310, 1929-1933, doi:10.1126/science.1121868.

Gurnett, D. A., et al. (2008), An overview of radar soundings of the Martian ionosphere from the Mars Express spacecraft, Adv. Space Res., 41, 1335-1346, doi:10.1016/j.asr.2007.01.062.

Haider, S. A., S. P. Seth, E. Kallio, and K. I. Oyama (2002), Solar EUV and electron-proton-hydrogen atom-produced ionosphere on Mars: Comparative studies of particle fluxes and ion production rates due to different processes, Icarus, 159, 18-30, doi:10.1006/icar.2002.6919.

Hanson, W. B., S. Sanatani, and D. R. Zuccaro (1977), The Martian ionosphere as observed by the Viking retarding potential analyzers, J. Geophys. Res., 82, 4351-4363.

Hantsch, M. H., and S. J. Bauer (1990), Solar control of the Mars ionosphere, Planet. Space Sci., 38, 539-542.

Hinson, D. P. (2007), Mars Global Surveyor radio occultation profiles of the ionosphere-Reorganized, MGS-M-RSS-5-EDS-V1.0, vol. USA NASA JPL MORS 1102, NASA Planet. Data Syst., NASA Goddard Space Flight Cent., Greenbelt, Md.

Hinson, D. P., F. M. Flasar, A. J. Kliore, P. J. Schinder, J. D. Twicken, and R. G. Herrera (1997), Jupiter's ionosphere: Results from the first Galileo radio occultation experiment, Geophys. Res. Lett., 24, 2107-2110.

Hinson, D. P., J. D. Twicken, and E. T. Karayel (1998), Jupiter's ionosphere: New results from Voyager 2 radio occultation measurements, J. Geophys. Res., 103, 9505-9520, doi:10.1029/97JA03689.

Hinson, D. P., R. A. Simpson, J. D. Twicken, G. L. Tyler, and F. M. Flasar (1999), Initial results from radio occultation measurements with Mars Global Surveyor, J. Geophys. Res., 104, 26,997-27,012. (Erratum, J. Geophys. Res., 105, 1717-1718, 2000.)

Kallio, E., and P. Janhunen (2001), Atmospheric effects of proton precipitation in the Martian atmosphere and its connection to the Mars-solar wind interaction, J. Geophys. Res., 106, 5617-5634, doi:10.1029/ 2000JA000239.

Kim, Y. H., W. D. Pesnell, J. M. Grebowsky, and J. L. Fox (2001), Meteoric ions in the ionosphere of Jupiter, Icarus, 150, 261-278, doi:10.1006/ icar.2001.6590.

Leblanc, F., J. G. Luhmann, R. E. Johnson, and E. Chassefiere (2002), Some expected impacts of a solar energetic particle event at Mars, $J$. Geophys. Res., 107(A5), 1058, doi:10.1029/2001JA900178.

Lyons, J. R. (1995), Metal ions in the atmosphere of Neptune, Science, 267, $648-651$.

Maguire, W. C., and A. C. Aikin (2006), Infrared signature of meteoritic material in the Martian atmosphere from MGS/TES limb observations, paper 60.23 presented at DPS Meeting, Am. Astron. Soc., Pasadena, Calif.

McAuliffe, J. P. (2006), Modelling meteor phenomena in the atmospheres of the terrestrial planets, Ph.D. thesis, Queen's Univ., Belfast, U. K.

McAuliffe, J. P., and A. A. Christou (2006), Modelling meteor ablation in the Venusian atmosphere, Icarus, 180, 8-22, doi:10.1016/ j.icarus.2005.07.012

McNeil, W. J., R. A. Dressler, and E. Murad (2001), Impact of a major meteor storm on Earth's ionosphere: A modeling study, J. Geophys. Res., 106, 10,447-10,466, doi:10.1029/2000JA000381.

McNeil, W. J., E. Murad, and J. M. C. Plane (2002), Models of meteoric metals in the atmosphere, in Meteors in the Earth's Atmosphere, pp. 265-287, Cambridge Univ. Press, New York.

Mendillo, M., S. Smith, J. Wroten, H. Rishbeth, and D. Hinson (2003), Simultaneous ionospheric variability on Earth and Mars, J. Geophys. Res., 108(A12), 1432, doi:10.1029/2003JA009961.
Mendillo, M., P. Withers, D. Hinson, H. Rishbeth, and B. Reinisch (2006), Effects of solar flares on the ionosphere of Mars, Science, 311, 11351138, doi:10.1126/science. 1122099

Molina-Cuberos, G. J., H. Lammer, W. Stumptner, K. Schwingenschuh, H. O. Rucker, J. J. López-Moreno, R. Rodrigo, and T. Tokano (2001), Ionospheric layer induced by meteoric ionization in Titan's atmosphere, Planet. Space Sci., 49, 143-153.

Molina-Cuberos, G. J., O. Witasse, J.-P. Lebreton, R. Rodrigo, and J. J. López-Moreno (2003), Meteoric ions in the atmosphere of Mars, Planet. Space Sci., 51, 239-249.

Morgan, D. D., D. A. Gurnett, D. L. Kirchner, R. L. Huff, D. A. Brain, W. V. Boynton, M. H. Acuña, J. J. Plaut, and G. Picardi (2006), Solar control of radar wave absorption by the Martian ionosphere, Geophys. Res. Lett., 33, L13202, doi:10.1029/2006GL026637.

Morgan, D. D., D. A. Gurnett, D. L. Kirchner, J. L. Fox, E. Nielsen, and J. J. Plaut (2008), Variation of the Martian ionospheric electron density from Mars Express radar soundings, J. Geophys. Res., 113, A09303, doi:10.1029/2008JA013313.

Moses, J. I., and S. F. Bass (2000), The effects of external material on the chemistry and structure of Saturn's ionosphere, J. Geophys. Res., 105 7013-7052, doi:10.1029/1999JE001172.

Nielsen, E. (2004), Mars Express and MARSIS, Space Sci. Rev., 111, 245 262 .

Nielsen, E., H. Zou, D. A. Gurnett, D. L. Kirchner, D. D. Morgan, R. Huff, R. Orosei, A. Safaeinili, J. J. Plaut, and G. Picardi (2006), Observations of vertical reflections from the topside Martian ionosphere, Space Sci. Rev., 126, 373-388, doi:10.1007/s11214-006-9113-y.

Nielsen, E., D. D. Morgan, D. L. Kirchner, J. Plaut, and G. Picardi (2007), Absorption and reflection of radio waves in the Martian ionosphere, Planet. Space Sci., 55, 864-870, doi:10.1016/j.pss.2006.10.005.

Pätzold, M., et al. (2004), MaRS: Mars Express Orbiter Radio Science, in Mars Express: The Scientific Payload, Eur. Space Agency Spec. Publ., ESA SP-1240, 141-163. (Available at http://sci.esa.int/science-e/www/ object/index.cfm? fobjectid=34885)

Pätzold, M., S. Tellmann, B. Häusler, D. Hinson, R. Schaa, and G. L. Tyler (2005), A sporadic third layer in the ionosphere of Mars, Science, 310, 837-839, doi:10.1126/science. 1117755 .

Pätzold, M., et al. (2007), The structure of Venus' middle atmosphere and ionosphere, Nature, 450, 657-660, doi:10.1038/nature06239.

Pätzold, M., S. Tellmann, B. Häusler, M. K. Bird, G. L. Tyler, A. A. Christou, and P. Withers (2008), A sporadic layer in the lower ionosphere of Venus resulting from meteor infall, Geophys. Res. Lett., doi:10.1029/ 2008GL035875, in press.

Pesnell, W. D., and J. Grebowsky (2000), Meteoric magnesium ions in the Martian atmosphere, J. Geophys. Res., 105, 1695-1708, doi:10.1029/ 1999JE001115.

Rishbeth, H., and O. K. Garriott (1969), Introduction to Ionospheric Physics, Academic, New York.

Rishbeth, H., and M. Mendillo (2004), Ionospheric layers of Mars and Earth, Planet. Space Sci., 52, 849-852, doi:10.1016/j.pss.2004.02.007.

Smith, M. D. (2008), Spacecraft observations of the Martian atmosphere, Annu. Rev. Earth Planet. Sci., 36, 191-219, doi:10.1146/annurev.earth.36.031207.124334.

Tyler, G. L., G. Balmino, D. P. Hinson, W. L. Sjogren, D. E. Smith, R. Woo, S. W. Asmar, M. J. Connally, C. L. Hamilton, and R. A. Simpson (1992), Radio Science investigations with Mars Observer, J. Geophys. Res., 97, 7759-7779

Tyler, G. L., G. Balmino, D. P. Hinson, W. L. Sjogren, D. E. Smith, R. A. Simpson, S. W. Asmar, P. Priest, and J. D. Twicken (2001), Radio science observations with Mars Global Surveyor: Orbit insertion through one Mars year in mapping orbit, J. Geophys. Res., 106, 23,327-23,348, doi:10.1029/2000JE001348

Tyler, G. L., et al. (2007), MGS RST science data products, MGS-M-RSS5-SDP-V1.0, vol. USA NASA JPL MORS 1038, NASA Planet. Data Syst., NASA Goddard Space Flight $\bar{C}$ ent., Greenbelt, Md.

Waite, J. H., Jr., and T. E. Cravens (1987), Current review of the Jupiter, Saturn, and Uranus ionospheres, Adv. Space Res., 7(12), 119-134, doi:10.1016/0273-1177(87)90210-9.

Wang, J.-S., and E. Nielsen (2003), Behavior of the Martian dayside electron density peak during global dust storms, Planet. Space Sci., 51, $329-338$.

Witasse, O., and A. F. Nagy (2006), Outstanding aeronomy problems at Venus, Planet. Space Sci., 54, 1381-1388, doi:10.1016/j.pss.2006. 04.028 .

Witasse, O., J.-F. Nouvel, J.-P. Lebreton, and W. Kofman (2001), HF radio wave attenuation due to a meteoric layer in the atmosphere of Mars, Geophys. Res. Lett., 28, 3039-3042, doi:10.1029/2001GL013164.

Withers, P. (2006), Mars Global Surveyor and Mars Odyssey Accelerometer observations of the Martian upper atmosphere during aerobraking, Geophys. Res. Lett., 33, L02201, doi:10.1029/2005GL024447. 
Withers, P. (2008), Theoretical models of ionospheric electrodynamics and plasma transport, J. Geophys. Res., 113, A07301, doi:10.1029/ 2007JA012918.

Withers, P., and M. Mendillo (2005), Response of peak electron densities in the Martian ionosphere to day-to-day changes in solar flux due to solar rotation, Planet. Space Sci., 53, 1401-1418, doi:10.1016/ j.pss.2005.07.010.

Withers, P., M. Mendillo, and D. Hinson (2006), Space weather effects on the Mars ionosphere due to solar flares and meteors, paper EPSC2006-A00190 presented at European Planetary Science Congress, Eur. Planet. Network, Berlin.
Withers, P., M. Mendillo, M. Pätzold, S. Tellmann, A. A. Christou, and J. Vaubaillon (2007), Comparison of ionospheric observations and dynamical predictions of meteor showers at Mars, paper 59.08 presented at DPS Meeting, Am. Astron. Soc., Orlando, Fla.

K. Cahoy and D. P. Hinson, Department of Electrical Engineering, Stanford University, Stanford, CA 94305, USA.

M. Mendillo and P. Withers, Center for Space Physics, Boston University, 725 Commonwealth Avenue, Boston, MA 02215, USA. (withers@bu.edu) 